\title{
The involvement of microRNAs in neurodegenerative diseases
}

\author{
Simona Maciotta ${ }^{1,2}$, Mirella Meregalli ${ }^{1}$ and Yvan Torrente ${ }^{1 *}$ \\ Stem Cell Laboratory, Department of Pathophysiology and Transplantation, Centro Dino Ferrari, Università degli Studi di Milano, Fondazione IRCCS Cà Granda \\ Ospedale Maggiore Policlinico, Milan, Italy \\ ${ }^{2}$ Diabetes Research Institute, University of Miami Miller School of Medicine, Miami, FL, USA
}

Edited by:

Alessandro Cellerino, Scuola

Normale Superiore, Italy

Reviewed by:

Daniele Bano, Deutsches Zentrum

für Neurodegenerative

Erkrankungen, Germany

Sebastian Kadener, The Hebrew

University, Israel

\section{${ }^{*}$ Correspondence:}

Yvan Torrente, Stem Cell Laboratory, Department of Pathophysiology and

Transplantation, Centro Dino Ferrari,

Università degli Studi di Milano,

Fondazione IRCCS Cà Granda

Ospedale Maggiore Policlinico, Via

Francesco Sforza 35, 20122 Milan,

Italy

e-mail:yvan.torrente@unimi.it
Neurodegenerative diseases (NDDs) originate from a loss of neurons in the central nervous system and are severely debilitating. The incidence of NDDs increases with age, and they are expected to become more common due to extended life expectancy. Because no cure is available, these diseases have become a major challenge in neurobiology. The increasing relevance of microRNAs (miRNAs) in biology has prompted investigation into their possible involvement in neurodegeneration in order to identify new therapeutic targets. The idea of using miRNAs as therapeutic targets is not far from realization, but important issues need to be addressed before moving into the clinics. Here, we review what is known about the involvement of miRNAs in the pathogenesis of NDDs. We also report the miRNA expression levels in peripheral tissues of patients affected by NDDs in order to evaluate their application as biomarkers of disease. Finally, discrepancies, innovations, and the effectiveness of collected data will be elucidated and discussed.

Keywords: microRNA, neurodegenerative diseases, biomarker, Parkinson's disease, Alzheimer's disease, amyotrophic lateral sclerosis, Huntington's disease

\section{INTRODUCTION}

Neurodegenerative diseases (NDDs) are a family of disorders characterized by progressive loss of neuronal function and structure, resulting in neuronal death in the nervous system. Different types of NDDs exist, depending on the neuron population affected; the most common are Alzheimer's disease (AD), Parkinson's disease (PD), Huntington's disease (HD), and amyotrophic lateral sclerosis (ALS). A commonality of NDDs is that they are not monogenic or polygenic diseases, and they are even more complicated because several events take part in the pathogenesis independent of genetic mutations. The molecular events responsible for neurodegeneration include oxidative stress, axonal transport deficits, protein oligomerization and aggregation, calcium deregulation, mitochondrial dysfunction, neuron-glial interactions, neuroinflammation, DNA damage, and aberrant RNA processing. The greatest risk factor for neurodegeneration is advancing age in combination with mitochondrial DNA mutation and oxidative stress damage. Other possible causes include gender, poor education, endocrine conditions, oxidative stress, inflammation, stroke, hypertension, diabetes, smoking, head trauma, depression, infection, tumors, vitamin deficiencies, immune and metabolic conditions, and chemical exposure. Because the pathogenesis of many of these diseases remains unknown, the role of environmental factors needs to be considered.

In the last few decades, NDDs have become a major challenge in neurobiology due to their enormous and growing social and economic implications in society. For the same reason, increasing research efforts have investigated the underlying molecular mechanisms in order to find a cure. Based on the latest evidence reviewed here, miRNA deregulation is emerging as a contributor to neurodegeneration by influencing most of the mechanisms responsible for NDDs. Neurodegeneration can also be considered to be an RNA disorder (Johnson et al., 2012) in which microRNAs play a major role. Studying miRNA involvement in NDDs might also provide targets for innovative therapies. Until now, patients affected by NDDs have been surgically and pharmacologically treated without obtaining a resolute therapy, which is due primarily to the fact that therapeutic approaches for NDDs require the modulation of multiple targets and molecular pathways because they are multigenic diseases. Based on the evidence that a single miRNA can influence several target genes, a whole disease phenotype could potentially be modified by modulating a single miRNA molecule, which makes these RNA molecules very intriguing from a therapeutic point of view. Furthermore, the identification of deregulated miRNAs in patients affected by NDDs or any other disease might allow earlier diagnosis and the monitoring of disease progress. The main challenge of using proteins as targets for routine diagnostics is low sensitivity, reproducibility, and specificity (Johnson et al., 2012). In conclusion, the aim of this review is to elucidate the broad implications of miRNAs in NDDs, but also to point out the need to overcome technical difficulties related to the study of miRNAs in NDDs. Finally, we also report in detail what has been discovered thus far regarding the involvement of miRNAs in different NDDs in order to evaluate their potential as therapeutic targets. 


\section{NON-CODING RNAs}

The sequencing of the human genome has demonstrated that the transcriptional output of the human genome is extremely rich in non-coding RNAs (ncRNAs) (Lipovich et al., 2010). Since this discovery, expectations regarding ncRNAs have increased exponentially. More importantly, the expectations have been supported by the development of next-generation sequencing technologies, which have revealed thousands of unknown ncRNAs. The vocabulary for ncRNAs is still far from saturated. The fascination of functional non-protein coding RNAs is that they represent a means for an organism's cells (cells that are genetically identical) to develop unique identities and functions. RNA is part of a mechanism that exerts control over DNA to guarantee the expression of a specific repertoire of genes at the appropriate level and with the appropriate timing. Two important classes of functional RNAs can be distinguished: long non-coding RNAs (lncRNAs) and small RNAs. LncRNAs account for the majority of transcription, they have no unifying structure or function, and they are solely defined as RNA transcripts greater than 200 nucleotides in length with no coding potential (Ponting et al., 2009). Relatively few lncRNAs have been characterized functionally, but increasing evidence suggests important roles for the thousands of uncharacterized transcripts. LncRNAs have been shown to target proteins to specific genomic loci, affecting transcription patterns (Plath et al., 2003; Silva et al., 2003; Kohlmaier et al., 2004; Zhao et al., 2008); to modulate the activity of proteinbinding partners (Dreyfuss et al., 2002; Allen et al., 2004; Espinoza et al., 2004; Feng et al., 2006; Shamovsky et al., 2006; Mariner et al., 2008); to function as precursors for small RNAs (Kapranov et al., 2007; Fejes-Toth et al., 2009) to affect the processing of other RNAs (Hellwig and Bass, 2008); and to modulate translation, DNA methylation, and chromatin.

In contrast to lncRNAs, the biogenesis and function of small RNAs is well known and can be divided into five classes: (i) short interfering (si) RNAs (Elbashir et al., 2001a), (ii) small temporal (st) RNAs (Pasquinelli et al., 2000), (iii) heterochromatic siRNAs (Reinhart and Bartel, 2002), (iv) tiny non-coding RNAs (Ambros et al., 2003), and (v) micro (mi) RNAs (LagosQuintana et al., 2001; Lau et al., 2001; Lee et al., 2001).These small RNAs are processed from longer precursors and loaded into an Argonaute (Ago) family member within a large effector protein complex. The typical function of small RNAs is to mediate the post-transcriptional gene silencing (PTGS) of target RNA transcripts. The best understood class of small RNAs is miRNAs, which were first discovered by Lee et al. (1993). miRNAs are 21-22nt single-stranded RNA molecules that inhibit gene expression by binding to a complementary sequence in the 3'UTR of target genes (Bartel, 2004). These molecules originate from longer transcripts (pri-miRNA) that are processed by Drosha nuclease to yield a short hairpin "pre-miRNA," which is then processed by Dicer to generate a double-stranded RNA of 21-22nt. Only one of the two strands is loaded into the RNA-induced silencing complex (RISC) that identifies target mRNA based on sequence complementarity with the miRNA. One of the core components of RISC is member of the Argonaute (Ago) protein family, in particular Ago1 and Ago2. After association with RISC, the choice of post-transcriptional repression is determined by sequence complementarity of the miRNA with its binding sequence on the $3^{\prime} \mathrm{UTR}$ of target mRNA: mRNA cleavage will happen when there is sufficient complementarity, otherwise inhibition of protein translation will occur. (Hammond et al., 2000; Elbashir et al., 2001a,b; Nykanen et al., 2001; Martinez et al., 2002; Schwarz et al., 2002). The relevance of miRNAs has increased with time; they are currently known to be involved in almost all biological processes and developmental programs (Bartel and Bartel, 2003; Carrington and Ambros, 2003; Hunter and Poethig, 2003). The first evidence that ncRNAs play a key role in neurodevelopment is the widespread transcription of ncRNAs in the developing mammalian brain (Lagos-Quintana et al., 2002; Krichevsky et al., 2003; Sempere et al., 2004; Smirnova et al., 2005; Bak et al., 2008). Next generation sequencing allowed the identification of a group of miRNAs that are enriched in the brain and whose expression varies according to area of the brain (Landgraf et al., 2007). In particular, neuronal-specific miRNAs have been demonstrated to control neuronal differentiation, excitability, and function. These brain-enriched miRNAs play a role in a wide range of neurodegenerative pathologies as disease-causing genes, biomarkers, or actors in pathogenesis. The idea of using miRNAs as therapeutic targets is not far from being realized. Two miRNA-based therapeutic approaches can be applied: miRNA mimics and antimiRNAs. miRNA mimics are small RNA molecules with the same sequence as the mature miRNA of interest that are used to downregulate the expression of target proteins mimicking the miRNA of interest. The desired effect is over-expression of miRNAs and down-regulation of their target mRNA, which can be used as a protective therapeutic strategy. This strategy has some important challenges that need to be overcome before moving into the clinic. First, the possibility exists that many out off object proteins might also be down-regulated because they are targets of the miRNA of interest. Second, the half-lives of mimics in vivo are not well known. Third, treating the brain with miRNA mimics is difficult because they need to pass through the blood-brain barrier (BBB). The second approach is to deliver RNA molecules with a sequence complementary to the miRNA of interest. Stoffel's group designed "antagomirs," RNA snippets conjugated to cholesterol molecules that help the RNA enter a cell (Krutzfeldt et al., 2005). The limit of antagomirs as a possible tool for treating NDDs is that they are not able to cross the $\mathrm{BBB}$ and require a local injection. Another strategy to inhibit endogenous miRNAs is to deliver synthetic sponge mRNA, which contains several complementary binding sites for the miRNA of interest (Kluiver et al., 2012a,b). Certain long ncRNAs are able to base-pair with small RNAs, inhibiting the ability of miRNAs to bind to their targets. Therefore, lncRNAs are analogous to how artificial miRNA sponges function (Ebert et al., 2007). This hypothesis was demonstrated by Franco-Zorrilla et al. (2007) with the long ncRNA induced by phosphate starvation 1 (IPS1) in Arabidopsis thaliana (Catarecha et al., 2007). Future prospects regarding the administration of miRNAs as therapeutics for NDDs will be discussed later.

\section{NEURODEGENERATIVE DISEASES AND miRNAs miRNAs IN PARKINSON'S DISEASE (PD)}

PD is the second most common NDD, estimated to occur in approximately $1 \%$ of individuals $>60$ years of age, with $4.1-4.6$ million people affected worldwide. PD is a progressive neurodegenerative disorder characterized clinically by bradykinesia, 
tremor, rigidity, and eventually postural instability (Shtilbans and Henchcliffe, 2012). These symptoms are attributed to a loss of dopaminergic neurons of the substantia nigra. The pathology spreads to involve other brain regions, including the amygdala, cingulate gyrus, and higher cortical regions, resulting in the development of dementia and psychosis. The disease itself is quite heterogeneous, and symptom progression is variable (Mouradian, 2012).

Despite rigorous research efforts, patient management and clinical research are still hampered by suboptimal methods for diagnosis, refining the prognosis, predicting individual responses to therapeutic interventions, and tracking disease progression. The critical reliance of dopaminergic neurons on a functioning miRNA network has been demonstrated in both cultured cells and in vivo (Kim et al., 2007). The miRNA machinery is important in NDDs in general and in PD in particular because the recognition of the amount of certain pathogenic proteins in specific neuronal populations is critical for the survival of neurons involved in the pathogenesis of disease. No cure is currently available for PD, and ongoing therapies are only directed at treating the most bothersome symptoms. Treatment approaches include medication (dopaminergic administration) and surgical therapy. Other strategies include general lifestyle modifications (rest and exercise), physical therapy, support groups, occupational therapy, and speech therapy. Nevertheless, new experimental therapies are under investigation and ongoing clinical trials are testing the efficacy of anti-inflammatory (pioglitazone) and parasympathomimetic (rivastigmine) drugs, ganglioside administration, and stemcell-based therapies. Even though PD is a multigenic disease, one of the most promising therapeutic approaches is to compensate biologically for the genetic defects responsible for $\mathrm{PD}$ pathogenesis. Some efforts have been made in this direction in the field of miRNAs, and the results are encouraging, even if far from clinical implementation.

\section{miR-7/miR-153 regulation of $\alpha$-synuclein}

A negative correlation has been reported with specific miRNAs for two of the genes involved in PD: $\alpha$-synuclein (SNCA) and leucine-rich repeat kinase2 (LRRK2). SNCA localizes in presynaptic terminals, where it associates with the plasma membrane. The protein is widely expressed in the adult brain, particularly the neocortex, hippocampus, and substantia nigra (Jakes et al., 1994; Mori et al., 2002; Wislet-Gendebien et al., 2008). The 3'UTR of the human protein is more than twice as long as the coding sequence and highly conserved (Sotiriou et al., 2009). This reports simply a relevant role for the $3^{\prime}$ in stabilizing SNCA mRNAs and regulating its translation into protein. Point mutations and gene duplication and triplication events in the SNCA locus have been identified in a number of families with autosomal dominant early onset PD (Singleton et al., 2003; Wood-Kaczmar et al., 2006). Higher expression of wild-type SNCA and expression of the three mutant forms of SNCA give rise to insoluble aggregates that constitute the main structure of the Lewy Bodies (Masliah et al., 2000; Tan and Skipper, 2007; Saiki et al., 2011). Thus, downregulation of SNCA represents a possible mechanism for resolving PD. Two miRNAs have been demonstrated to inhibit the expression of SNCA: miR-7 and miR-153 (Junn et al., 2009; Doxakis,
2010) (Table 1). Both miRNAs are highly enriched in the brain (Bak et al., 2008), and their sequences are conserved among different organisms. miR-153, in particular, is conserved across vertebrate species. Both miRNAs inhibit SNCA mRNA and protein (Junn et al., 2009; Doxakis, 2010), with an additive effect (Doxakis, 2010). Interestingly, the expression profile of these two miRNAs in the brain of post-natal day 1 mice is similar to $\alpha$ synuclein protein and mRNA, and has been localized primarily to the neurons of the midbrain, hippocampus, and cortex (Junn et al., 2009; Doxakis, 2010). Co-localization of a miRNA with its target gene suggests tight control of the amount of the target gene produced.

\section{miR-205/let-7/miR-184* regulation of LRRK2}

LRRK2 is a member of the leucine-rich repeat kinase family and is present largely in the cytoplasm, but also associates with

\section{Table 1 | Specific target genes of miRNAs involved in} neurodegeneration are listed.

\begin{tabular}{|c|c|c|c|}
\hline NDDs & miRNAs & Target genes & References \\
\hline \multirow[t]{6}{*}{ PD } & miR-7 & DP & $\begin{array}{l}\text { Junn et al., 2009; } \\
\text { Doxakis, } 2010\end{array}$ \\
\hline & miR-153 & E2F1 & Doxakis, 2010 \\
\hline & let-7 & LRRK2 & $\begin{array}{l}\text { Junn et al., 2009; } \\
\text { Gehrke et al., } 2010\end{array}$ \\
\hline & miR-184* & LRRK2 & Gehrke et al., 2010 \\
\hline & miR-433 & FGF20 & $\begin{array}{l}\text { Davis et al., 2005; } \\
\text { Wang et al., 2008a,b }\end{array}$ \\
\hline & miR-205 & LRRK2 & Cho et al., 2013 \\
\hline \multirow[t]{12}{*}{$A D$} & miR-106a, $-520 c$ & APP & Patel et al., 2008 \\
\hline & miR-20a, $-106 a / b,-17$ & APP & $\begin{array}{l}\text { Hebert and De } \\
\text { Strooper, } 2009\end{array}$ \\
\hline & miR-16, -101 & APP & Long and Lahiri, 2011 \\
\hline & $\begin{array}{l}\text { miR-147, }-655 \\
-323-3 p,-644,-153\end{array}$ & APP & Delay et al., 2011 \\
\hline & miR-124 & APP splicing & Smith et al., 2011 \\
\hline & miR-29a, $-29 b-1,-9$ & BACE1 & $\begin{array}{l}\text { Hebert and De } \\
\text { Strooper, } 2009\end{array}$ \\
\hline & miR-298, -328, -195 & BACE1 & $\begin{array}{l}\text { Boissonneault et al., } \\
\text { 2009; Zhang, } 2012\end{array}$ \\
\hline & miR-124 & BACE1 & Fang et al., 2012 \\
\hline & miR-98 & IGF1 & Hu et al., 2013 \\
\hline & miR-181c, -137 & SPTLC1 & $\begin{array}{l}\text { Geekiyanage and } \\
\text { Chan, } 2011\end{array}$ \\
\hline & miR-29a, $-29 b-1,-9$ & SPTLC2 & $\begin{array}{l}\text { Geekiyanage and } \\
\text { Chan, } 2011\end{array}$ \\
\hline & miR-34a & TAU & Dickson et al., 2013 \\
\hline \multirow[t]{2}{*}{ ALS } & miR-206 & HDAC4 & Williams et al., 2009 \\
\hline & miR-9 & $\mathrm{NEFH}$ & Haramati et al., 2010 \\
\hline \multirow[t]{3}{*}{ HD } & miR-9 & REST & Juliano et al., 2008 \\
\hline & miR-9* & CoREST & Juliano et al., 2008 \\
\hline & miR-196a & mut-Htt & Cheng et al., 2013 \\
\hline
\end{tabular}

NDDs, neurodegenerative diseases; $P D$, Parkinson's Disease; AD, Alzheimer Disease; ALS, Amiotrophic Lateral Sclerosis; HD, Huntington's disease. 
the mitochondrial outer membrane. It is highly expressed in the brain, with the highest levels of expression in the hippocampus and striatum (Galter et al., 2006; Melrose et al., 2006). LRRK2 is involved in the early development of neuronal processes (Parisiadou et al., 2009) and gain-of-function mutations cause familial as well as sporadic PD (Zimprich et al., 2004). Recent investigations in flies have demonstrated that the mutated form of LRRK2 (mut-LRRK2) is responsible for a reduced miRNAmediated gene repression. This is due to the fact that mut-LRKK2 physically interacts with Ago1 and Ago2-two components of the RISC - inducing their down-regulation in aged Drosophila Melanogaster (Gehrke et al., 2010). Gehrke et al. also investigated the possible target mRNAs whose translation is induced by mutLRRK2 and identified E2F1 and DP. Flies expressing mut-LRRK2 were in fact characterized by higher expression levels of E2F1 and DP, and down-regulation of E2F1 and DP suppressed the death of dopaminergic neurons. Finally Gehrke $S$ et al. demonstrated that miR-184* and let-7, respectively, repressed E2F1 and DP (Table 1) and that inhibition of these miRNAs in wild-type animals was sufficient to phenocopy pathogenic LRRK2. In line with this, both let-7 and miR-184* have been demonstrated to regulate dopaminergic survival and activity (Junn et al., 2009; Gehrke et al., 2010). Regardless the role of mut-LRRK2 in PD, latest studies investigated the consequences of wild-type LRRK2 deregulation in PD pathogenesis. In particular LRRK2 gene locus was identified as a genetic risk factor for the more common sporadic PD (Satake et al., 2009; Simon-Sanchez et al., 2009), indicating that alteration of its expression might be part of PD etiology. Moreover, up-regulation of LRKK2 in an animal model of PD quickened neurodegeneration (Lin et al., 2009). Basing on these evidences, Cho et al. analyzed the expression levels of LRKK2 (protein and mRNA) in the frontal cortex tissue of 8 sporadic PD patients and relative control subjects. No differences in the mRNA levels were found but affected brains were characterized by higher expression levels of LRRK2 protein, suggesting a miRNA-mediated regulation of this protein. In silico analysis has demonstrated a predicted binding site for miR-205 in the $3^{\prime} \mathrm{UTR}$ of LRKK2 and in vitro experiments confirmed a direct inhibition of LRKK2 via miR205. Finally they demonstrated that transfection of miR-205 in the neurons expressing a PD-related LRKK2 R1441G mutant prevented the neurite outgrowth defects (Cho et al., 2013).

\section{miR-433 regulation of FGF20}

Fibroblast growth factor 20 (FGF20) is a neurotrophic factor preferentially expressed in the substantia nigra that sustains the survival of dopaminergic neurons (Ohmachi et al., 2000, 2003). In contrast to this pro-survival activity, FGF20 treatment of human neuroblastoma cell line SH-SY5Y increases the amount of endogenous SNCA, demonstrating an anti-survival role of FGF20 in dopaminergic neurons. Single nucleotide polymorphisms (SNPs) in the $3^{\prime} \mathrm{UTR}$ of this gene (i.e., rs1721100, ss20399075, and rs12720208) have been found to be associated with PD (Wang et al., 2008a). Importantly, the latest polymorphism is within the miR-433 binding site (Davis et al., 2005), which is highly enriched in the brain. Wang et al. demonstrated that SNP rs12720208 avoids inhibition by FGF20 through miR-433 (Wang et al., 2008a). Finally, subsequent investigations failed to confirm a relationship between the rs12720208 genotype, FGF20, and SNCA. These discrepancies are often related to the ethnic origins or genetic backgrounds of PD patients.

\section{miRNAs in the peripheral tissues of PD patients}

The use of biomarkers in PD is a moot point, and no reliable biomarker exists for this NDD, with the exception of the monogenetic form of PD. With the increasing relevance of miRNAs in NDDs, some efforts have been made to investigate the possibility of miRNAs as biomarkers. In particular, qRT-PCR analyses of peripheral blood isolated from eight untreated PD patients (NT) and eight control subjects (CTR) showed that the expression levels of three miRNAs (miR-1, miR-22*, and miR-29a) distinguish NT from CTR (Margis et al., 2011) (Table 2). A second study was based on qRT-PCR analyses of plasma obtained from $31 \mathrm{NT}$ and 25 CTR (Cardo et al., 2013) and identified seven over-expressed miRNAs (miR-181c, miR-331-5p, miR-193a-3p, miR-196b, miR454, miR-125a-3p, and miR-137) in NT (Table 2). Discrepancies may be attributed to intrinsic differences between the sample types (Table 2 ).

\section{miRNAs IN ALZHEIMER'S DISEASE (AD)}

$\mathrm{AD}$ is the most common form of dementia in people over 65 years of age. The disease is characterized by progressive neuronal loss and inflammation affecting memory, language, behavior, and cognition. The disease is characterized by amyloid- $\beta(\mathrm{A} \beta)$ deposition, neurofibrillary tangle (NFT) formation, and extensive neuronal degeneration in the brain. $A \beta$ is derived from the sequential cleavage of amyloid precursor protein (APP) by beta-site APP-cleaving enzyme 1 (BACE1) and the $\gamma$-secretase complex. The precise pathological mechanisms underlying $\mathrm{AD}$ are currently unknown. Clinical and research evidence indicates that aberrant regulation of miRNA-dependent gene expression is closely associated with molecular events responsible for $A \beta$ production, NFT formation, and neurodegeneration (Hebert and De Strooper, 2007, 2009; Hebert et al., 2008; Wang et al., 2008b). The regulation of APP is complex but represents a great challenge in the treatment of $\mathrm{AD}$ patients. Current drug discovery approaches in $\mathrm{AD}$ have focused on (i) preventing $\mathrm{A} \beta$ formation or increasing "normal" APP processing through the inhibition of $\gamma$ - and $\beta$-secretase or the activation of $\alpha$-secretase activity (Palop and Mucke, 2010; Saido and Leissring, 2012; Schenk et al., 2012); removing existing amyloid deposits via immunotherapeutic approaches,e.g., antibodies or vaccines against amyloid (Schenk et al., 2012). The miRNA field has moved in the same direction, and miRNAs have been discovered to regulate APP expression in three different ways: directly, indirectly, and by regulating the alternative splicing of its mRNA.

\section{Direct inhibition of APP via miRNAs}

Direct regulation of APP is mediated by miRNA binding to a specific sequence in the 3'UTR. Several miRNAs that inhibit APP expression in vitro have been identified, including miR-106a and miR-520c; members of the miR-20a family (e.g., miR-20a, miR106a/b, miR-17) (Hebert and De Strooper, 2009); miR-16 and miR-101 (Vilardo et al., 2010; Long and Lahiri, 2011); and miR147, miR-655, miR-323-3p, miR-644, and miR-153 (Delay et al., 
Table 2 | miRNAs deregulation in NDDs patients.

\begin{tabular}{|c|c|c|c|c|c|}
\hline NDD & miRNAs & Source & Changes & $\begin{array}{l}\text { Patients }(P) \\
\text { and controls }(C)\end{array}$ & References \\
\hline \multirow[t]{4}{*}{ PD } & miR-133b & SNC & Down-regulation & $3 \mathrm{P}, 5 \mathrm{C}$ & Kim et al., 2007 \\
\hline & miR-34b/c & SNC & Down-regulation & $11 P, 6 C$ & Minones-Moyano et al., 2011 \\
\hline & $\operatorname{miR}-1,-22^{*},-29 a$ & Peripheral blood & Down-regulation & 8P, 8C & Margis et al., 2011 \\
\hline & $\begin{array}{l}\text { miR-181c, }-331-5 p,-193 a-p,-196 b,-454 \\
-125 a-3 p,-137\end{array}$ & Plasma & Over-expression & 31P,25 C & Cardo et al., 2013 \\
\hline \multirow[t]{7}{*}{$A D$} & miR-34a, -181b & PBMC & Over-expression & $16 P, 16 C$ & Schipper et al., 2007 \\
\hline & $\begin{array}{l}\operatorname{miR}-26 a,-27 b,-30 e-5 p,-34 a,-92,-125,-145 \\
-200 c,-381,-422 a,-423\end{array}$ & \multirow{2}{*}{$\begin{array}{l}\text { Hippocampus, } \\
\text { cerebellum, medial } \\
\text { frontal gyrus }\end{array}$} & Over-expression & $15 P, 12 C$ & \multirow[t]{4}{*}{ Cogswell et al., 2008} \\
\hline & miR-9, $-132,-146 b,-212$ & & Down-regulation & & \\
\hline & $\begin{array}{l}\text { let-7f, miR-105, }-125 a,-135 a,-138,-141,-151, \\
-186,-191,-197,-204,-205,-216,-302 b,-30 a-5 p, \\
-30 a-3 p,-30 b,-30 c,-30 d,-32,-345,-362,-371, \\
-374,-375,-380-3 p,-429,-448,-449,-494,-501, \\
-517,-517 b,-518 b, 518 f, 520 a *, 526 a\end{array}$ & \multirow[t]{2}{*}{ Cerebrospinal fluid } & Over-expression & $10 P, 10 C$ & \\
\hline & $\begin{array}{l}\text { miR-10a, }-10 b,-125,-126 *,-127,142-5 p,-143, \\
-146 b,-154,-15 b,-181 a,-181 c,-194,-195, \\
-199 a^{*},-214,-221,-328,-422 b,-451,-455,-497, \\
-99 a\end{array}$ & & Down-regulation & & \\
\hline & miR-9, -125b, -146a, 155 & $\begin{array}{l}\text { Cerebrospinal fluid and } \\
\text { brain tissue derived } \\
\text { extracellular fluid }\end{array}$ & Over-expression & $3 P, 3 C$ & Lukiw, 2007 \\
\hline & miR-26b & Substanzia nigra & Over-expression & $10 \mathrm{P}, 8 \mathrm{C}$ & Absalon et al., 2013 \\
\hline \multirow[t]{5}{*}{ ALS } & miR-338-3p & \multirow{2}{*}{ Whole blood } & Over-expression & $12 \mathrm{P}, 8 \mathrm{C}$ & De Felice et al., 2012 \\
\hline & miR-451, $-1275,-328,-638,-149,-665,-583$ & & Down-regulation & & \\
\hline & miR-27a, $-155,-146 a,-32-3 p$ & $\begin{array}{l}\mathrm{CD}^{1} 4^{+} \mathrm{CD}^{-} 6^{-} \\
\text {monocytes }\end{array}$ & Over-expression & $8 P, 8 C$ & Butovsky et al., 2012 \\
\hline & $\operatorname{miR}-146^{*},-524-5 p, 582-3 p$ & Spinal cord & Over-expression & $5 P, 3 C$ & Campos-Melo et al., 2013 \\
\hline & miR-24-2* $,-142-3 p,-142-5 p,-1461,-146 b,-155$ & Spinal cord & Over-expression & $16 \mathrm{P}, 12 \mathrm{C}$ & Koval et al., 2013 \\
\hline \multirow[t]{7}{*}{ HD } & miR-29a, -330 & \multirow[t]{2}{*}{ Brodmann's area 4} & Over-expression & & Johnson et al., 2008 \\
\hline & miR-132 & & Down-regulation & & \\
\hline & miR-132, $-196,-486$ & \multirow{2}{*}{ Brodmann's area 4} & Over-expression & 19P, 7C & Packer et al., 2008 \\
\hline & $\begin{array}{l}\operatorname{miR}-9,-9 *,-124,-29 b, 17-3 p,-22,-485-5 p, 500 \\
-222\end{array}$ & & Down-regulation & 19P, 7C & \\
\hline & miR-100, -151-3p,-16, -219-2-3p, -27b, -451, -92a & $\begin{array}{l}\text { Frontal cortex and } \\
\text { striatum }\end{array}$ & Over-expression & $11 \mathrm{P}, 11 \mathrm{C}$ & Marti et al., 2010 \\
\hline & $\operatorname{miR}-128,-139-3 p,-222,-382,-433,-483-3 p$ & $\begin{array}{l}\text { Frontal cortex and } \\
\text { striatum }\end{array}$ & Down-regulation & $11 \mathrm{P}, 11 \mathrm{C}$ & Marti et al., 2010 \\
\hline & miR-34b & Plasma & Over-regulation & $27 \mathrm{P}, 12 \mathrm{C}$ & Gaughwin et al., 2011 \\
\hline
\end{tabular}

NDDs, neurodegenerative diseases; PD, Parkinson's Disease; AD, Alzheimer Disease; ALS, Amiotrophic Lateral Sclerosis; HD, Huntington's disease. 
2011) (Table 1). Only a few of these miRNAs are deregulated in the brains of AD patients (Hebert et al., 2008; Nunez-Iglesias et al., 2010), and it is difficult to determine which of these miRNAs regulate APP in vivo.

\section{Indirect inhibition of APP via miRNAs}

Indirect inhibition of APP via miRNAs is through the direct down-regulation of genes in pathways regulating the expression, function, or processing of this protein. $\beta$-secretase BACE1, insulin-like growth factor 1 (IGF-1), and serine palmitoyltransferase (SPT) influence APP expression and are modulated by miRNAs.

BACE1 plays a pivotal role in regulating $A \beta$ production by cleaving APP and releasing APP $\beta$. Hebert et al. demonstrated the in vitro inhibition of BACE1 by miR-29a, miR-29b-1, and miR9 and confirmed an association between the down-regulation of these miRNAs and AD (Hebert et al., 2008). Mice over-expressing miR-29c are characterized by the down-regulation of BACE1 levels, demonstrating an in vivo effect on BACE1 modulation (Zong et al., 2011). Other studies demonstrated a negative correlation between BACE1 and miR-298/miR-328/miR-195 in several animal models of $\mathrm{AD}$ and confirmed direct inhibition in different mouse cell lines (Boissonneault et al., 2009; Zhu et al., 2012). Finally, the most conserved and abundantly expressed nervous system-specific miR-124 has been shown to inhibit BACE1 expression in cultured rat PC12 cell lines and primary cultured hippocampal neurons, a cellular model of AD (Fang et al., 2012).

De-regulation of IGF-1-mediated signaling has been correlated with $\mathrm{AD}$ (Rosario, 2010). IGF-1 function in the brain includes $A \beta$ clearance from the brain and phosphorylation of tau (Hong and Lee, 1997; Vargas et al., 2011). Hu et al. showed that the expression of miR-98 negatively correlates with the IGF-1 expression level in a mouse model of AD. Furthermore, overexpression of miR-98 in cellular models of $\mathrm{AD}$ is responsible for the down-regulation of IGF-1, enhanced A $\beta$ production, and tau phosphorylation (Hu et al., 2013).

SPT, a heterodimer composed of serine palmitoyltransferase long chain 1 (SPTLC1) and serine palmitoyltransferase long chain 2 (SPTLC2), is the first rate-limiting enzyme in the de novo ceramide synthesis pathway (Hannun and Obeid, 2008). Membrane ceramides are known to contribute to AD pathology by facilitating the mislocation of BACE1 and $\gamma$-secretase to lipid rafts, thereby promoting $A \beta$ formation (Lee et al., 1998; Vetrivel et al., 2005). Interestingly, SPT is increased in the brain of sporadic AD patients (Geekiyanage and Chan, 2011) with up-regulation of several miRNAs, including miR-137, miR-181c, miR-9, miR-29a, miR-29b-1, and miR-15. In vitro luciferase assay confirmed direct inhibition of SPTLC1 by miR-181c and miR-137 and of SPTLC2 by miR-29a, miR-29b1, and miR-9. Moreover, a negative correlation has been demonstrated between the expression levels of these miRNAs and their relative target genes, SPTLC1 and SPTLC2, in the frontal cortices of sporadic AD patients (Geekiyanage and Chan, 2011).

\section{miRNAs regulating the alternative splicing of APP}

Human APP exists as three major isoforms (APP751, APP770, and APP695) originating from alternative splicing. Isoforms
APP751 and APP770 are widely expressed and contain the Kunitz protease inhibitor (KPI) domain encoded by exon7, but only APP770 contains the putative glycosylation domain OX2 encoded by exon8. The APP695 isoform is majorly expressed in neurons (Zhang et al., 2011) and contains neither the KPI nor OX2 domains. Changes in the expression profile of neuronal APP are associated with an increase in $\mathrm{A} \beta$ production (Donev et al., 2007). Higher expression of APP isoforms containing exons 7 and 8 is found in various areas of the brains of $\mathrm{AD}$ patients (Golde et al., 1990; Neve et al., 1990; Jacobsen et al., 1991; Tanzi et al., 1993; Rockenstein et al., 1995). To investigate the involvement of miRNAs in the regulation of APP splicing, Smith et al. created a forebrain-specific Dicer conditional knock-out mouse in which post-mitotic neurons were characterized as having increased levels of APP751 and APP770 isoforms. Because miR-124 plays a pivotal role in neuronal maintenance and splicing (Makeyev et al., 2007; Papagiannakopoulos and Kosik, 2009), Smith et al. induced the ectopic expression of miR-124 in Neuro2a cells, which was enough to induce the skipping of exons 7 and 8 by inhibiting polypyrimidine tract binding protein 1 (PTB1). In addition, and supporting this observation, lower expression of miR-124 was measured in the brains of AD patients (Smith et al., 2011).

\section{miR-34a/miR-26b regulation of tau protein}

The microtubule-associated protein tau promotes the assembly and stability of microtubules (Weingarten et al., 1975; Drubin and Kirschner, 1986). It is involved in many NDDs, collectively known as tauopathies (Lee et al., 2001). In the case of AD, tau is hyperphosphorylatated and accumulates in the cytoplasm where it gives origin to intraneuronal protein aggregates known as NFTs (Kosik et al., 1986; Nukina and Ihara, 1986; Wood et al., 1986). Although alterations in tau protein are not considered the earliest event in $\mathrm{AD}$ pathogenesis, reduction in its expression levels may be safe and beneficial to prevent or treat AD (Rapoport et al., 2002; Roberson et al., 2007; Ittner et al., 2010; Vossel et al., 2010). In this optics, Dickson et al. investigated the role of the $3^{\prime} \mathrm{UTR}$ of human tau mRNA in regulating tau expression. Using different prediction algorithms, they found several miRNA-binding sites and they were able to validate direct inhibition of human tau by miR-34a (Dickson et al., 2013). Another approach to inhibit NFT formation is represented by regulating the phosphorilation status of tau protein. Tau is in fact a phosphoprotein that contains more than 80 potential phosphorylation sites (Hanger and Noble, 2011). As mentioned above, hyperphosphorilation of tau causes insoluble aggregates into the cytoplasm of neurons. In regard, Absalon et al. identified a specific miRNA (miR-26b) that rises in the substantia nigra at early stages of $\mathrm{AD}$ (Braak III) and remains elevated in the pathological area of human $\mathrm{AD}$ brain during disease progression. A target mRNA of miR-26b was confirmed to be Retinoblastoma $(\mathrm{Rb})$. Both over-expression of miR-26b and down-regulation of $\mathrm{Rb}$ in primary cortical neurons showed activation of cyclin-dependent kinase $5(\mathrm{Cdk} 5)$ and enhanced tau phosphorylation, followed by apoptosis and neurodegeneration in vitro (Absalon et al., 2013). AntagomiR-26b based therapy might not only decrease tau phosphorylation and NTF formation, but also enhances neuronal survival. 


\section{miR-146 regulation of presenilin}

As described by Haas et al. the APP undergoes successive proteolysis by $\beta$ - and $\gamma$-secretases to produce the $A \beta$ that characteristically deposits in AD brain (Hass et al., 2009). $\gamma$-Secretases is a large complex of four integral membrane proteins, with presenilin (PSEN) as the catalytic subunit. Dominant mutations in the genes encoding for presenilins (PSEN1 and PSEN2) are the most common cause of familial early-onset Alzheimer's disease (Brouwers et al., 2008). These mutations alter the biochemical character of the $\gamma$-secretase complex and its interaction with the APP substrate, so that a longer and aggregation-prone form of $A \beta$ is produced (Mucke and Selkoe, 2011). It is also to note that presenilins function is likely to be relevant to the development of sporadic AD. For all above reasons, presenilins together with $\beta$ - and $\gamma$ secretases are top targets for AD drug discovery. In addition to its role in $A \beta$ generation, PSEN2 was demonstrated to modulate the microglia activity (Jayadev et al., 2013). More in detail, Jayadev et al. demonstrated that in vivo deficiency of PSEN2 associated with exaggerated pro-inflammatory state in microglia. Basing on this evidence, they hypothesized that presenilin disfunctions could contribute to AD neurotoxic inflammation (Jayadev et al., 2010). In order to elucidate the underlining molecular mechanisms, PSEN2 knockout (KO) and wt microglia were analyzed for differential miRNA expression. The expression profiles of several miRNAs involved in the regulation of innate immune signaling were perturbed in PSENKO microglia, including miR-146 that is a potent negative regulator of innate immunity. This observation suggested that PS2 modulates cytokine responses via inhibition of miR-146. In line with this evidence, the target mRNA of miR146a IRAK-1 (interleukin-1 receptor-associated kinase-1) was increased in PS2KO microglia. One of the function of IRAK-1 is to be a mediator of IL-1 (interleukin-1) signaling (Cao et al., 1996) and a critical regulator of Toll-like receptor (TLR) signal transduction (Swantek et al., 2000). When activated, IRAK-1 binds to NFkB thereby promoting nuclear localization and transcriptional activity (Flannery and Bowie, 2010). Indeed PS2KO vs. wt. microglia showed increased $\mathrm{NFkB}$ activity upon stimulation with lipopolysaccharide (LPS). Jayadev et al. strongly demonstrated that PSEN2 influences microglia activity but the exact mechanism by which PSEN2 carries out this task via miR-146 modulation still need to be elucidated (Jayadev et al., 2013).

\section{miRNA profile of the brain and peripheral tissues in AD}

In most cases, $\mathrm{AD}$ can only be diagnosed by neuropsychological studies, neuroimaging, and clinical data from patients that allow characterization as probable or possible AD patients (Mckhann et al., 1984) with a sensitivity of $93 \%$ and specificity of $55 \%$. Furthermore, diagnosis is far more difficult in early and unusual presentations of the disease. Several research efforts have examined miRNAs in order to identify potential biomarkers. In 2007, the first small-scale profiling of miRNAs was performed on the hippocampal region of fetal, adult, and AD brains (Lukiw, 2007). Since then, several large-scale analyses have been performed on different $\mathrm{AD}$ tissues, including brain, peripheral blood, and cerebrospinal fluid (CSF) (Schipper et al., 2007; Cogswell et al., 2008; Hebert et al., 2008; Wang et al., 2008a; Nunez-Iglesias et al., 2010; Shioya et al., 2010). Nevertheless, miRNA expression studies on $\mathrm{AD}$ patients have had either no or very little overlap in miRNA changes (Table 2). Schipper et al. analyzed blood mononuclear cells (BMC) from patients with sporadic AD using miRNA microarray analyses and found two miRNAs that are significantly up-regulated in $\mathrm{AD}$ subjects: miR-34a and miR181 b (Schipper et al., 2007) (Table 2). Cogswell et al. performed qRT-PCR analysis on brain tissue and CSF from AD patients, identifying a set of miRNAs, so-called AD-specific miRNAs, that are differentially expressed in the brain and altered in the CSF of AD patients (Cogswell et al., 2008) (Table 2). Finally, Lukiw et al. group recently characterized the miRNome of AD CSF and short post-mortem interval brain tissue-derived extracellular fluid (ECF) using fluorescent miRNA array, finding significant increases in miR-9, miR-125b, miR-146a, and miR-155 in AD CSF and ECF (Lukiw, 2007) (Table 2).

\section{miRNAs IN AMYOTROPHIC LATERAL SCLEROSIS (ALS)}

ALS is often referred to as "Lou Gehrig's Disease." It is a progressive, idiopathic, fatal NDD that affects nerve cells in the brain and spinal cord. Motor neuron loss gives rise to malfunctions in the muscle tissue, causing weakness, atrophy, and ultimately paralysis and death within 3 or 5 years of symptom onset. The disease occurs worldwide with an incidence of approximately $2 \times 10^{5}$ and a prevalence of approximately $6-8 \times 10^{5}$. Currently, there is only one FDA-approved compound; riluzole does not resolve the disease, but slows progression and extends survival with modest effects. The discovery of small molecules that change the course of disease in ALS is desirable. With the increasing relevance of miRNAs, many recent research efforts have investigated the role of these small RNA molecules in the pathogenesis of ALS. The data that have been obtained are encouraging but still in their infancy, as they demonstrated an involvement but are far from proposing a solution. Nevertheless, if we are able to improve our understanding of the pathogenesis of ALS, it could lead to the development of early and specific diagnostic methods and extend the life expectancy of ALS patients. No definitive diagnostic tests or biomarkers exist for ALS, and neurologists rely on clinical criteria for diagnosis. The development of novel biomarkers to evaluate disease progression could give us the ability to refine the design of therapeutic trials and reduce the costs of clinical trials (Kiernan et al., 2011).

\section{miR-206 and re-innervation}

One of the most promising studies toward an innovative approach to cure ALS was conducted by Williams et al. (2009). miRNAs are involved in the stress response in skeletal muscle (Van Rooij and Olson, 2007). Because ALS is characterized by paralysis of the lower limbs, Williams et al. investigated the miRNome of muscles isolated from the lower limbs of an animal model of ALS, SOD1 transgenic mice. MyomiR-206 (Chen et al., 2006; Rao et al., 2006) was strongly induced, and its up-regulation coincided with the onset of symptoms. After severing the sciatic nerve of wildtype mice to induce denervation of the lower leg muscles, higher expression levels of miR-206 were observed 10 days after surgery in fast-twitch muscles, suggesting the involvement of this miRNA in re-innervation. This hypothesis was confirmed when miR206 was knocked out in SOD1 transgenic mice, demonstrating 
accelerated progression of ALS and shortened survival (Williams et al., 2009). The underlying molecular mechanism was investigated and miR-206 was found to induce the secretion of fibroblast growth factor binding protein 1 (FGFBP1) from muscle by inhibiting Histone deacetylase 4 (HDAC4) translation. FGFBP1 potentiates the effect of FGFs in the promotion of presynaptic differentiation at the neuromuscular junction (Fox et al., 2007).

\section{miRNA biogenesis and ALS}

Multiple studies have identified several dominant mutations in the $43-\mathrm{kDa}$ trans-activating response region (TAR) DNA-binding protein (TDP-43) in both sporadic and familial ALS patients that are associated with other NDDs (Kabashi et al., 2008; Sreedharan et al., 2008; Pesiridis et al., 2009; Lagier-Tourenne et al., 2010). A functionally related gene, fused in sarcoma/translocation in liposarcoma (FUS/TLS), is also mutated in ALS (Kwiatkowski et al., 2009; Vance et al., 2009). These two DNA/RNA-binding proteins physically interact with one another and are physiologically involved in the regulation of RNA transcription and splicing (Giordana et al., 2010; Lagier-Tourenne et al., 2010). The exact mechanism by which these proteins become pathogenic in ALS remains uncertain, but the most assessed hypothesis is related to their nuclear/cytoplasmic imbalance (Kwiatkowski et al., 2009; Vance et al., 2009; Giordana et al., 2010). Moreover, Ling et al. discovered that ALS-associated forms of TDP-43 have longer halflives, contributing to TDP-43 aggregation in ALS patients, and they have an increased affinity for FUS/TLS (Ling et al., 2010).

By combining tandem-affinity purification and quantitative mass-spectrometry analysis, Ling et al. discovered that TDP43 is associated with multiple hnRNP proteins and the Drosha microprocessing complex (Ling et al., 2010). Similarly, data indicated that Drosha protein is a putative FUS interactor (Gregory et al., 2004). Association with Drosha and mislocation of TDP43 and FUS/TLS suggests de-regulation of miRNA biogenesis in ALS. Independent from this study, knocking down TDP-43 in the human Hep-3B cell line was later shown to replicate the changes occurring in the total miRNA population (Buratti et al., 2010). A relationship was also demonstrated between TDP-43 and brain-enriched miR-9; loss of Drosophila TDP-43 was characterized by down-regulation of miR-9a and TDP-43 influenced sensory organ precursor (SOP) cells in Drosophila through miR-9a (Li et al., 2013). Regarding FUS/TLS, its downregulation in neuroblastoma cell line SK-N-BE affected the biogenesis of a large class of miRNAs, including neuronal isoforms. FUS/TLS is recruited at the chromatin, where it directly binds pri-miRNAs, facilitating Drosha loading (Morlando et al., 2012).

\section{miR-9 regulation of neurofilaments}

Neurofilaments are components of the neuronal cytoskeleton and provide structural support to the axons. They are assembled from light, medium, and heavy subunits, creating three different types of neurofilaments: light (NEFL), medium (NEFM), and heavy $(\mathrm{NEFH})$. If the expression of neurofilaments is not well orchestrated, axonal cytoskeletal defects occur (Julien, 1999; Liem and Messing, 2009). Perturbation of the fine neurofilaments is associated with the development of human ALS (Figlewicz et al., 1994; Tomkins et al., 1998; Al-Chalabi et al., 1999). The 3'UTRs of neurofilament-encoding genes appear to interact with an uncharacterized trans-acting factor that is attenuated in ALS (Haramati et al., 2010), which might be miRNAs. In support of this hypothesis, ablation of Dicer1 in post-mitotic post-natal motor neurons fails to coordinate neurofilament subunit stoichiometry, but only the expression levels of NEFH were perturbed. Prediction analyses found one and nine binding sites for miR-9 in the $3^{\prime}$ UTR of NEFL and NEFH, respectively. Direct inhibition of NEFH by miR-9 was confirmed by in vitro experiments (Table 1), but no luciferase assays were performed to validate the NEFL/miR-9 interaction. Thus, dysregulation of neurofilament stoichiometry in several motoneuron diseases is due to miR-9 loss (Haramati et al., 2010). No further efforts have been made to understand the involvement of miR-9 in ALS.

\section{miRNA profile of the spinal cord in ALS}

The first study aiming to characterize the miRNA profile in the spinal cord of sporadic ALS patients was conducted by Campos-Melo et al. (2013). They used a quantitative qRT-PCRbased array method to screen 664 human miRNAs from the spinal cords of three healthy controls and five ALS patients; they identified 246 down-regulated and 10 up-regulated miRNAs (Table 2). This was the only study reporting such a mass decrease in the miRNA profile for NDDs. Interestingly, many of the de-regulated miRNAs were predicted to have a binding site in the $3^{\prime}$ UTR of NEFL, and consistent inhibition was demonstrated for miR-146*, miR-524-5p, and miR-582-3p (Campos-Melo et al., 2013). Around the same time, Koval et al. characterized the expression of 613 miRNAs using miRNA microarray experiments and the spinal cords of diseased rats and mice. Using individual assays, 11 miRNAs were confirmed in the diseased mice, 10 in SOD ${ }^{G 93 A}$ rats, and 6 in ALS patients (miR-24-2*, miR-142-3p, miR-142-5p, miR-1461, miR-146b, and miR-155) (Table 2). More importantly, miR-155 was increased in both sporadic and familial ALS patients, and when its expression was inhibited in the brain of SOD1 ${ }^{G 93 A}$ rats in vivo, both survival and disease duration were increased (Koval et al., 2013).

\section{miRNAs in the peripheral tissues of ALS patients}

De Felice et al. performed the first and only miRNA profiling of leukocytes isolated from blood to identify characteristic patterns in sporadic ALS patients (De Felice et al., 2012). Briefly, leukocytes were isolated from the blood of 8 patients and 12 healthy controls and screened for the expression of 911 human miRNAs using microarray technology. Eight miRNAs (miR-338-3p, miR-451, miR-1275, miR-328, miR-638, miR-149, miR-665, and miR-583) were de-regulated in ALS patients (Table 2). Among these miRNAs, miR-338-3p was previously found in brain tissue from ALS patients (Shioya et al., 2010).This study detected, for the first time, specific disease-related changes in miRNAs at an earlier stage of sporadic ALS.

Another study was performed on peripheral tissues from ALS patients; in particular, the analyses were restricted to a subgroup of monocytes $\left(\mathrm{CD} 14^{+} \mathrm{CD} 16^{-}\right)$isolated from ALS patients. This population was chosen because its murine analog (Ly6 ${ }^{\mathrm{Chi}}$ monocytes) isolated from SOD1 mice has a pronounced pro-inflammatory profile (gene and miRNA expression) prior to disease onset and is recruited to the spinal cord, where 
the cells proliferate during disease progression. The human $\mathrm{CD} 14^{+} \mathrm{CD}_{16}{ }^{-}$monocytes isolated from ALS patients and $\mathrm{Ly}^{\mathrm{Chi}}$ monocytes isolated from SOD1 mice had a unique inflammatory miRNA profile. Ly $6^{\text {Chi }}$ diseased monocytes were characterized by the up-regulation of let- 7, miR-15b, miR-16, miR-27a, miR-34a, miR-132, miR-146a, miR-155, miR-223, and miR-451 (Table 2). Human $\mathrm{CD} 14^{+} \mathrm{CD}^{-} 6^{-}$ALS monocytes had higher expression levels of miR-27a, miR-155, miR-146a, and miR-32-3p (Butovsky et al., 2012) (Table 2). Finally, the authors underlined the potential role of these miRNAs as biomarkers of ALS.

\section{miRNAs AND HUNTINGTON'S DISEASE (HD)}

$\mathrm{HD}$ is an incurable neurodegenerative condition caused by CAG repeat expansion in the huntingtin gene $(\mathrm{Htt})$. HD patients manifest cognitive defects and motor control impairment due to neuronal dysfunction characterized by progressive loss of cortical and striatal neurons. Neuronal death happens due to the toxicity associated with the mutant Htt protein and loss of the neuroprotective effects of the wild-type protein (Cattaneo et al., 2005). Little is known about the function of $\mathrm{Htt}$, but its mutant form affects cellular phenotype and viability (Zuccato et al., 2010). Several genes have been found to be altered in the brain of HD patients (Cha, 2007), and many transcription factors (TFs) interact with $\mathrm{Htt}$ and are recruited to the mutant Htt aggregates (Sugars and Rubinsztein, 2003) in the brain. Recruitment to Htt aggregates prevents TFs from binding to DNA and eliciting their functions. More importantly, mutant Htt inhibits the formation of processing bodies ( $\mathrm{P}$ bodies) by interacting with Agol and Ago2, which are involved in miRNA biogenesis (Savas et al., 2008). Thus, miRNA dysregulation is expected in the brain of HD patients. Currently, no cure exists for HD; all of the treatments are palliative. RNA therapy has emerged as a powerful tool for modifying the disease course by targeting mutant HTT mRNA for degradation.

\section{miRNA profile in the brain of HD patients}

Htt was demonstrated to interact with repressor element 1 silencing transcription factor (REST), the essential transcriptional repressor also known as neuron-restrictive silencing factor (NRSF), in neurons (Zuccato et al., 2003; Ooi and Wood, 2007). In control individuals, Htt sequesters REST in the cytoplasm of neurons and prevents the repressor from binding to DNA; in HD patients the mutant Htt does not associate with REST, which relocates to the nucleus of HD neurons and represses many of its target genes. One of the target genes of REST is BDNF, which is essential for neuron survival (Zuccato et al., 2003).

Based on the presence of REST binding sites in the genome, Johnson et al. were able to identify a set of REST-target miRNAs in the human genome (miR-9-1, 9-3, 29a, 29b-1, 124a-1, 124a$2,124 a-3,132,135 b, 139,203,204,212,330$, and 346) that are also brain or neuron-specific (Johnson et al., 2008). Among these miRNAs, four (miR-29a, miR-124a, miR-132, and miR-330) were found to be decreased in the cortex of R6/2 mice, an animal model of HD. Furthermore, their known target mRNAs were increased in R6/2 mice (Johnson et al., 2008) Johnson et al. then analyzed the expression profile of miR-29a, miR-124a, miR-132, and miR$135 \mathrm{~b}$ in parietal cortical tissues from control and HD individuals; only down-regulation of miR-132 was confirmed in the human samples (Table 2). Otherwise, the expression levels of miR-29a and miR-330 were increased and miR-124a did not differ between HD and control subjects (Johnson et al., 2008) (Table 2).

Packer et al. investigated whether miRNAs correlate with disease progression in HD patients by analyzing the expression profile of predicted REST-regulated miRNAs in Brodmann's area 4 (BA4) isolated from control and HD grade 1-4 brain samples (Packer et al., 2008). Five miRNAs (miR-9, miR-9*, miR-29b, miR-124a, and miR-132) were significantly different with increasing HD grade (Packer et al., 2008). Otherwise, no correlation with disease progression was observed for miR-139, miR-135b, and miR-212. Next, a qRT-PCR-based miRNA array platform was used to evaluate the expression profiles of 365 mature miRNAs in the BA4 cortex from control and early stage HD (grades 1 and 2) patients. The de-regulation of additional miRNAs, including miR-486, miR-196a, miR-17-3p, miR-22, miR-485-5p, miR-500, and miR-222, was found (Packer et al., 2008).

Finally, Marti et al. analyzed the expression profile of miRNAs in the frontal cortex and striatum of HD patients using three different techniques: RNA sequencing, microarray, and qRT-PCR. miR-100, miR-151-3p, miR-16, miR-219-2-3p, miR-27b, miR451, and miR-92a were found to be over-expressed in diseased tissues in all three experiments (Marti et al., 2010). Similarly, miR128, miR-139-3p, miR-222, miR-382, miR-433, and miR-483-3p were decreased in the HD brain tissue in all three experiments (Marti et al., 2010).

Based on the data above, 30 miRNAs are increased and $24 \mathrm{miR}$ NAs are decreased in the brains of HD patients. De-regulation of 33 of the 54 miRNAs associated with HD can be attributed to four TFs that are altered in the HD brain; TP53, REST, E2F1, and GATA4 (Sinha et al., 2012). In particular, TP53 is involved in processing the primary miRNA transcript to the mature miRNA (Suzuki et al., 2009). Because intronic miRNAs are transcribed at the same levels as the host genes if oriented in the same direction (Baskerville and Bartel, 2005; Wang et al., 2009), Sinha et al. investigated a possible relationship between the host genes and intronic miRNAs in HD. Thirty-one of the 54 miRNAs deregulated in the brains of HD patients are encoded within the introns, and the expression of some of these miRNAs correlates with the expression levels of their host genes (Sinha et al., 2012).

\section{miR-9/9*-REST/CoREST feedback in HD}

As mentioned above, the expression levels of miR-9 and miR9* are decreased in the cerebral cortex of HD-affected subjects. Interestingly these two miRNAs target REST and CoREST, respectively (Johnson and Bucley, 2009a). REST has been demonstrated to inhibit the expression of neuronal genes in non-neuronal cells, and under normal conditions it is retained in the cytoplasm by interacting with Htt. When Htt is mutated, REST no longer associates with $\mathrm{Htt}$, which then relocates and accumulates in the nucleus, where it inhibits the expression of several genes (Zuccato et al., 2003). Decreased levels of miR-9/9* in HD would increase the transcription of REST, amplifying the accumulation of this protein in the presence of mutated Htt. This phenomenon is further magnified because miR-9/9* transcription depends on REST. Thus, the translocation of REST to the nucleus in HD brain 
tissues explains the reduced expression of miR-9/miR9* (Johnson et al., 2009b).

\section{miR-196a and HTT expression}

Based on the results published by Packer et al. (2008) and on unpublished microarray data from transgenic monkeys with HD, Cheng et al. identified miR-196a as a possible miRNA involved in the pathogenesis of HD. To further investigate the role of this miRNA in HD, they co-transfected human embryonic kidney and murine neuroblastoma cell lines with two constructs: miR-196a mimic and the mutant form of Htt. These in vitro experiments showed for the first time that miR-196a suppresses the expression of mutant $\mathrm{Htt}$ at the mRNA and protein levels. Furthermore, this inhibition was not due to the direct binding of miR-196a to the3'UTR of mutated Htt. Otherwise, miR-196a predominantly suppressed Htt expression through the inhibition of protein synthesis and partly through enhanced protein degradation. To confirm these results in vivo, Cheng et al. generated a miR-196a transgenic mouse and bred it with transgenic mice expressing mutant $\mathrm{Htt}$ fused to green fluorescent protein (GFP). The expression of miR-196a and mutant Htt were up- and down-regulated, respectively, in the brain of double transgenic mice, confirming the in vitro results. Moreover, inhibition by miR-196a also occurred at later stages of the disease in double transgenic mice when more Htt aggregates accumulated. Because the double transgenic mouse model represents a model of over-expression, Chen et al. evaluated the inhibition of mutated Htt via miR-196a by transfecting induced pluripotent stem cells derived from individuals with HD (HD-iPSCs) with lentiviral vector encoding for miR-196a. As expected, untreated cells accumulated more mutated Htt aggregates, whereas cells transfected with miR-196a were characterized by lower expression of mutated Htt, suggesting that miR-196a can alleviate the pathological phenotypes in human samples. The downstream effect of miR-196a over-expression on Htt metabolism was investigated; the ubiquitin-proteosome system, gliosis, cAMP response element-binding protein pathway, and several neuronal regulatory pathways were implicated (Cheng et al., 2013). All of these evidences suggest a potential therapeutic role of miR-196a in HD.

\section{miRNAs in the peripheral tissues of HD patients}

Even though the ultimate trait biomarker is represented by mutated $\mathrm{Htt}$, many efforts have focused on identifying mRNAs or proteins with expression profiles that could correlate with disease progression. Gaughwin et al. developed a cell model of HD (HTT-Exon-1 over-expressing human cell line) in order to identify miRNA biomarkers. Briefly, they transfected an embryonal carcinoma-derived pluripotent cell line (NT2) capable of differentiating into neurons with Htt-Exon-1 construct carrying 23, 73, and 145 polyglutamine repeats. Microarray analysis revealed two known miRNAs (miR-34b and miR-1285) that are increased in the presence of 73Q-Htt and 145Q-Htt compared to23Q-Htt. Based on these data, they investigated the expression levels of miR-34b and miR-1285 in human plasma, demonstrating that they are detectable in human samples and bio-stable relative to proteins. When the investigation was expanded to plasma from HD patients, miR-34b was increased in pre-manifest
HD plasma relative to age-matched controls (Gaughwin et al., 2011). In contrast, no correlation was found for miR-1285. These results suggest that miR-34b behaves as a potential biomarker of HD prior to symptom onset. Despite the novelty of the results obtained, a limitation of this study was the small patient cohort, which needs to be enlarged.

\section{THERAPEUTIC mIRNAs FOR NDDs}

The essential properties of a drug are favorable bioavailability, a reasonable half-life, and few side effects. These requirements are dependent on the type of drug, the target organ, and on the delivery system used. An ideal vector for in vivo delivery of RNA molecules should be equipped with a cationic group for effective transfection, an endosomolytic group for endosomal escape, a surface modifier to decrease steric hindrance, which enhances circulation in the blood, and a targeting moiety to direct the delivery system at target cells or tissue (Whitehead et al., 2009). From the injection of miRNA agonists/antagonists and knockdown of target genes/endogenous miRNAs, physiological barriers represent the first obstacle to the efficacy of drug treatment. Many checkpoints are represented by glomerular filtration, hepatic metabolism, reticular endothelial system (RES) uptake, and endothelial barriers. If injected as naked molecules, RNA is subjected to nuclease degradation, which is responsible for $70 \%$ knockdown of drug efficacy within 1 min of administration (Mahato et al., 1995). To avoid the action of nucleases, chemical modification or non-viral carriers can be used (Borchard, 2001; Wang et al., 2002; Crooke, 2004; Juliano, 2005; Juliano et al., 2008). RNA particles $>200 \mathrm{~nm}$ delivered to liposomes, lipoplexes, polyplexes, or nanoparticles are subjected to phagocytosis by RES (Alexis et al., 2008), and those smaller than $100 \mathrm{~nm}$ are the target of hepatic Kupffer cells. Conjugation with non-viral carriers might induce marked toxicity because RNA molecules will also enter the non-targeted cells due to an interaction between the negatively charged cellular membrane and cationic carriers (Uyechi et al., 2001). This effect might be reduced by coating carriers with hydrophilic molecules (polyethylene glycol) or by conjugation with a ligand (e.g., surface receptor-specific antibodies) (Balyasnikova et al., 2002). Furthermore, RNA molecules can be associated with aptamers, monoclonal antibodies, or peptides to target specific cell surface receptors and the desired target in the body (Juliano, 2005; Chu et al., 2006; Kumar et al., 2008). After RNA molecules have passed these physiological barriers, they have to enter the target cells to elicit their actions. This means that they have to cross the cell membrane, escape endosomes, and localize in the nucleus. Therefore, nuclear-localization signals and cell-penetrating and endosomal-release signal peptides can influence the duration of action of injected RNA molecules (Jere et al., 2009).

In vivo delivery of RNA can be achieved two ways: systematically and locally (Figure 1). A great amount of drug is required when it is injected systemically. In contrast, local delivery allows a small amount of drug to be administered with reduced side effects (Pardridge, 2007; Pushparaj et al., 2008; Shen, 2008). Notably, systemic delivery is preferred when the target organ is the liver as the majority of systemically administered drug molecules localize to the liver. Efforts have been made to deliver RNA molecules across 


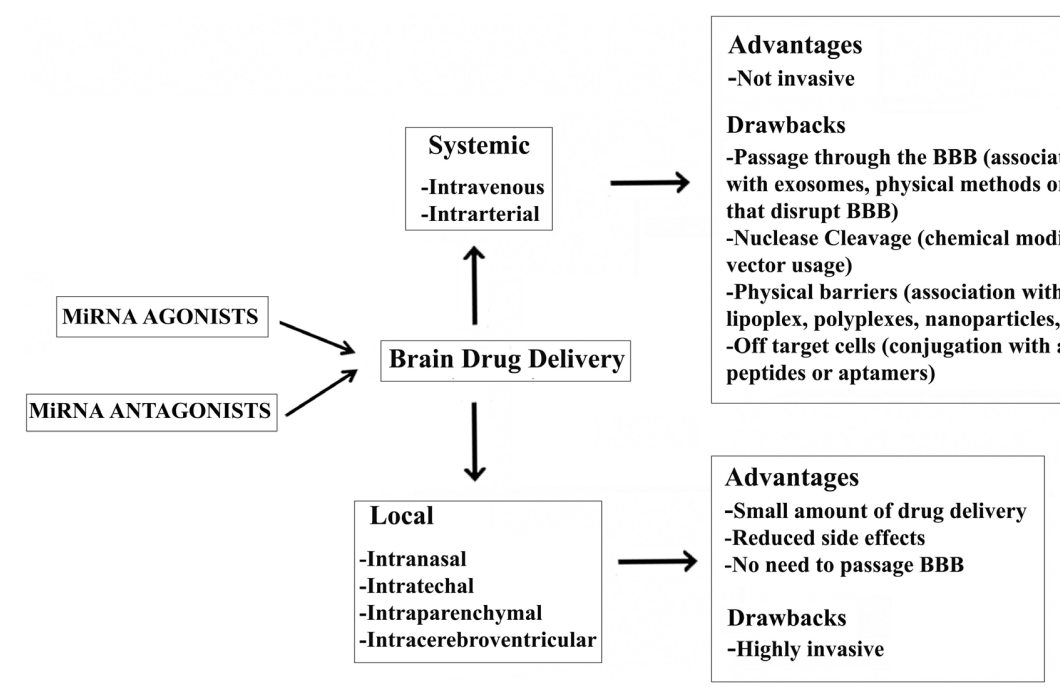

FIGURE 1 | Advantages and drawbacks of a miRNA-based therapy for the treatment of NDDs.

the $\mathrm{BBB}$ by in vivo systemic delivery, but it remains a major challenge in the treatment of NDDs. In particular, physical methods, such as ultrasound (Chen et al., 2010; Liu et al., 2010), and the intra-arterial infusion of compounds that disrupt the BBB (e.g., potassium channel agonists and minoxidil sulphate) increase the chances of overcoming the BBB (Ningaraj et al., 2007; Bidros et al., 2010). Recently, Alvarez-Erviti et al. experimented the delivery of RNA molecules associated with exosomes across the BBB. Exosomes are cell-derived vesicles that enable cell-to-cell communication by transferring RNA molecules and proteins. They have been shown to preserve mRNAs and miRNAs in the presence of RNase and subsequently deliver them to recipient cells (Valadi et al., 2007; Skog et al., 2008; Zomer et al., 2010). In particular, Alvarez-Erviti et al. isolated brain-targeting exosomes from dendritic cells bioengineered to express an exosomal membrane protein (Lamp 2b) fused to a ligand of the acetylcholine receptor. Exosomes were then loaded with siRNAs targeting BACE1 mRNA by electroporation and injected intravenously, resulting in a significant knock-down of BACE1 expression (Alvarez-Erviti et al., 2011).

Efficient local delivery strategies for the CNS are intranasal, intracerebroventricular, intrathechal, or intraparenchymal injection of naked RNAi formulated in isotonic saline buffer (Makimura et al., 2002). Adenoviral, lentiviral, and adenoassociated virus-based local delivery has also been performed in animal models of AD, HD (Harper et al., 2005), and ALS (Ralph et al., 2005), demonstrating significant improvement. Nevertheless, the strategy to locally deliver a drug to the brain is still far from normal practice because of the complexities associated with direct injection into the brain.

\section{CONCLUSION}

Following the discovery of miRNAs, their actions were investigated in almost all biological processes and, even more importantly, their central role in gene-expression regulation implicated in many human diseases (Subramanian et al., 2008; Thum et al., 2008; Eisenberg et al., 2009; Malumbres et al., 2009; Matkovich et al., 2009; Crist and Buckingham, 2010; Maciotta et al., 2012). miRNAs are of particular interest in understanding complex disorders, such as NDDs, because they can potentially regulate several pathways involved in the insurgence and progression of the disease. In the last few years, miRNAs have also been considered as biomarkers; they offer several advantages over mRNA or protein, including increased stability and biological relevance in many different diseases. In fact, miRNAs offer the possibility to link a biomarker with an altered biological process and therapy capable of targeting the pathological mechanism. miRNA-based therapeutic treatments for NDDs may follow two different strategies: miRNA over-expression (gain-of-function) or miRNA repression (loss-of-function) (Figure 1). The first approach might use miRNA-associated target gene specificity in order to down-regulate the expression of the aberrant gene within the cell of interest; the second should use miRNAs to directly influence the differentiation of neural stem cells (NSCs) (Palm et al., 2012).

In the last few years, the hypothesis that miRNAs could be involved in NDDs has gained support (Hebert and De Strooper, 2007) due to many experiments with different animal models, such as the fly and mouse. Much experimental data demonstrate that the miRNA network is necessary for neuron survival (Hebert and De Strooper, 2009). Experiments conducted in humans support the idea that changes in miRNA expression profiles or miRNA targets could increase the risk of major NDDs, such as $\mathrm{AD}$ and $\mathrm{PD}$ (Tables 1, 2).

miRNA research seems particularly promising for understanding not only the very prevalent and poorly understood sporadic forms of $\mathrm{AD}$, but also forms of PD. The challenge now is to understand the role of specific miRNAs in biological models and translate this knowledge to clinical studies (Hebert and De Strooper, 2009). 
The use of miRNAs as potential therapeutic targets remains controversial with regard to methods of delivery and target specificity. When considering a treatment for NDDs mediated by miRNA delivery, we have to evaluate its ability to pass through the BBB. In order to overcome the problem of the $\mathrm{BBB}$, several siRNA delivery systems are being developed for in vivo purposes, including vector-based, chemically modified, and "packaged" RNA oligonucleotides (Kim and Rossi, 2007). Progress in the latter area will immediately translate into progress in the miRNA area because both are based on the same principles. Both small RNAs regulate at the posttranscriptional level; therefore, miRNAs and siRNAs are chemically identical. However, the big question is whether these different approaches will result in clinically feasible therapies because of bioavailability and toxicity issues inherent to all of these approaches, and the BBB constitutes an enormous hurdle for the effective delivery of these experimental drugs in the brain.

Oligonucleotides can be effectively deployed in animal models, and RNA complexity provides the opportunity to uncover novel regulatory mechanisms and biomarkers. A limit to clinical miRNA use is that much remains to be improved in the prediction of target genes for both miRNAs and lncRNAs (Johnson et al., 2012). The most effective way of interfering with ncRNA action is likely not by targeting the RNA/target gene interaction itself, but to target the recruited epigenetic apparatus; this offers the advantage of exploiting a growing array of chemical compounds aimed at the active sites of chromatin modifiers (Kelly et al., 2010). At the very least, this expanded view of the importance of RNA, both protein-coding and non-coding, both small and large, offers an abundance of novel interactions to target that are distinct from the current focus on protein regulation in neurodegeneration.

Small ncRNAs add a novel and exciting layer of complexity to molecular neuronal biology. In addition, publications will exponentially increase in the years to come, which will provide novel insights into this recently discovered field of research (Hebert and De Strooper, 2009). A "many to many" relationship exists between miRNAs and their target mRNAs. The ability of a single miRNA to potentially target as many as 200 different miRNAs is well documented, but there is also evidence of single mRNA being targets of multiple miRNAs. To put this complex "many to many" relationship in a biological context, a comprehensive analysis of all miRNA targets suggested to be regulated by a single miRNA generally constitutes a biological network of functionally associated molecules in human cells. This evidence may represent a limitation for the use of regulatory small RNAs as a biomarker in NDDs or for future clinical trials to treat NDDs. However, miRNAs might help extract some biologically relevant targets among the high number of "predicted targets" of individual miRNAs, and potentially serves as a filter when using pathway analysis tools to understand the functional pathways affected by miRNA profile changes in NDDs.

In conclusion, many scientific questions remain to be addressed before efficient delivery and/or modulation of miRNAs in the brain will be possible (Krutzfeldt et al., 2005, 2007).

\section{ACKNOWLEDGMENTS}

This work was supported in part by grants from EU's Framework Programme 7 Optistem 223098, the Associazione ProductIDLa Nostra FamigliaLa Nostra Famiglia Fondo DMD Gli Amici di Emanuele, and by the Associazione Amici del Centro Dino Ferrari.

\section{REFERENCES}

Absalon, S., Kochanek, D. M., Raghavan, V., and Krichevsky, A. M. (2013). MiR-26b, upregulated in Alzheimer's disease, activates cell cycle entry, tauphosphorylation, and apoptosis in postmitotic neurons. J. Neurosci. 33, 14645-14659. doi: 10.1523/JNEUROSCI.1327-13.2013

Al-Chalabi, A., Andersen, P. M., Nilsson, P., Chioza, B., Andersson, J. L., Russ, C., et al. (1999). Deletions of the heavy neurofilament subunit tail in amyotrophic lateral sclerosis. Hum. Mol. Genet. 8, 157-164. doi: 10.1093/hmg/ 8.2.157

Alexis, F., Pridgen, E., Molnar, L. K., and Farokhzad, O. C. (2008). Factors affecting the clearance and biodistribution of polymeric nanoparticles. Mol. Pharm. 5, 505-515. doi: 10.1021/mp800051m

Allen, T. A., Von Kaenel, S., Goodrich, J. A., and Kugel, J. F. (2004). The SINEencoded mouse B2 RNA represses mRNA transcription in response to heat shock. Nat. Struct. Mol. Biol. 11, 816-821. doi: 10.1038/nsmb813

Alvarez-Erviti, L., Seow, Y., Yin, H., Betts, C., Lakhal, S., and Wood, M. J. (2011). Delivery of siRNA to the mouse brain by systemic injection of targeted exosomes. Nat. Biotechnol. 29, 341-345. doi: 10.1038/nbt.1807

Ambros, V., Lee, R. C., Lavanway, A., Williams, P. T., and Jewell, D. (2003). MicroRNAs and other tiny endogenous RNAs in C. elegans. Curr. Biol. 13, 807-818. doi: 10.1016/S0960-9822(03)00287-2

Bak, M., Silahtaroglu, A., Moller, M., Christensen, M., Rath, M. F., Skryabin, B., et al. (2008). MicroRNA expression in the adult mouse central nervous system. RNA 14, 432-444. doi: 10.1261/rna.783108

Balyasnikova, I. V., Yeomans, D. C., Mcdonald, T. B., and Danilov, S. M. (2002). Antibody-mediated lung endothelium targeting: in vivo model on primates. Gene Ther. 9, 282-290. doi: 10.1038/sj.gt.3301657

Bartel, B., and Bartel, D. P. (2003). MicroRNAs: at the root of plant development? Plant Physiol. 132, 709-717. doi: 10.1104/pp.103.023630

Bartel, D. P. (2004). MicroRNAs: genomics, biogenesis, mechanism, and function. Cell 116, 281-297. doi: 10.1016/S0092-8674(04)00045-5

Baskerville, S., and Bartel, D. P. (2005). Microarray profiling of microRNAs reveals frequent coexpression with neighboring miRNAs and host genes. RNA 11, 241-247. doi: 10.1261/rna.7240905

Bidros, D. S., Liu, J. K., and Vogelbaum, M. A. (2010). Future of convectionenhanced delivery in the treatment of brain tumors. Future Oncol. 6, 117-125. doi: $10.2217 /$ fon.09.135

Boissonneault, V., Plante, I., Rivest, S., and Provost, P. (2009). MicroRNA298 and microRNA-328 regulate expression of mouse beta-amyloid precursor protein-converting enzyme 1. J. Biol. Chem. 284, 1971-1981. doi: 10.1074/jbc.M807530200

Borchard, G. (2001). Chitosans for gene delivery. Adv. Drug Deliv. Rev. 52, 145-150. doi: 10.1016/S0169-409X(01)00198-3

Brouwers, N., Sleegers, K., and Van Broeckhoven, C. (2008). Molecular genetics of Alzheimer's disease: an update. Ann. Med. 40, 562-583. doi: 10.1080/07853890802186905

Buratti, E., De Conti, L., Stuani, C., Romano, M., Baralle, M., and Baralle, F. (2010). Nuclear factor TDP-43 can affect selected microRNA levels. FEBS J. 277, 2268-2281. doi: 10.1111/j.1742-4658.2010.07643.x

Butovsky, O., Siddiqui, S., Gabriely, G., Lanser, A. J., Dake, B., Murugaiyan, G., et al. (2012). Modulating inflammatory monocytes with a unique microRNA gene signature ameliorates murine ALS. J. Clin. Invest. 122, 3063-3087. doi: 10.1172/JCI62636

Campos-Melo, D., Droppelmann, C. A., He, Z., Volkening, K., and Strong, M. J. (2013). Altered microRNA expression profile in amyotrophic lateral sclerosis: a role in the regulation of NFL mRNA levels. Mol. Brain 6, 26. doi: 10.1186/17566606-6-26

Cao, Z., Henzel, W. J., and Gao, X. (1996). IRAK: a kinase associated with the interleukin-1 receptor. Science 271, 1128-1131. doi: 10.1126/science.271.5252.1128 
Cardo, L. F., Coto, E., De Mena, L., Ribacoba, R., Moris, G., Menendez, M., et al. (2013). Profile of microRNAs in the plasma of Parkinson's disease patients and healthy controls. J. Neurol. 260, 1420-1422. doi: 10.1007/s00415-013-6900-8

Carrington, J. C., and Ambros, V. (2003). Role of microRNAs in plant and animal development. Science 301, 336-338. doi: 10.1126/science.1085242

Catarecha, P., Segura, M. D., Franco-Zorrilla, J. M., Garcia-Ponce, B., Lanza, M., Solano, R., et al. (2007). A mutant of the Arabidopsis phosphate transporter PHT1;1 displays enhanced arsenic accumulation. Plant Cell 19, 1123-1133. doi: 10.1105/tpc.106.041871

Cattaneo, E., Zuccato, C., and Tartari, M. (2005). Normal huntingtin function: an alternative approach to Huntington's disease. Nat. Rev. Neurosci. 6, 919-930. doi: $10.1038 / \mathrm{nrn} 1806$

Cha, J. H. (2007). Transcriptional signatures in Huntington's disease. Prog. Neurobiol. 83, 228-248. doi: 10.1016/j.pneurobio.2007.03.004

Chen, J. F., Mandel, E. M., Thomson, J. M., Wu, Q., Callis, T. E., Hammond, S. M., et al. (2006). The role of microRNA-1 and microRNA-133 in skeletal muscle proliferation and differentiation. Nat. Genet. 38, 228-233. doi: 10.1038/ ng1725

Chen, P. Y., Liu, H. L., Hua, M. Y., Yang, H. W., Huang, C. Y., Chu, P. C., et al. (2010). Novel magnetic/ultrasound focusing system enhances nanoparticle drug delivery for glioma treatment. Neuro Oncol. 12, 1050-1060. doi: 10.1093/neuonc/noq054

Cheng, P. H., Li, C. L., Chang, Y. F., Tsai, S. J., Lai, Y. Y., Chan, A. W., et al. (2013). miR-196a Ameliorates Phenotypes of Huntington Disease in Cell, Transgenic Mouse, and Induced Pluripotent Stem Cell Models. Am. J. Hum. Genet. 93, 306-312. doi: 10.1016/j.ajhg.2013.05.025

Cho, H. J., Liu, G., Jin, S. M., Parisiadou, L., Xie, C., Yu, J., et al. (2013). MicroRNA-205 regulates the expression of Parkinson's disease-related leucinerich repeat kinase 2 protein. Hum. Mol. Genet. 22, 608-620. doi: 10.1093/ hmg/dds 470

Chu, T. C., Twu, K. Y., Ellington, A. D., and Levy, M. (2006). Aptamer mediated siRNA delivery. Nucleic Acids Res. 34:e73. doi: 10.1093/nar/gkl388

Cogswell, J. P., Ward, J., Taylor, I. A., Waters, M., Shi, Y., Cannon, B., et al. (2008). Identification of miRNA changes in Alzheimer's disease brain and CSF yields putative biomarkers and insights into disease pathways. J. Alzheimers Dis. 14, 27-41.

Crist, C. G., and Buckingham, M. (2010). Megarole for microRNA in muscle disease. Cell Metab. 12, 425-426. doi: 10.1016/j.cmet.2010.10.007

Crooke, S. T. (2004). Progress in antisense technology. Annu. Rev. Med. 55, 61-95. doi: 10.1146/annurev.med.55.091902.104408

Davis, E., Caiment, F., Tordoir, X., Cavaille, J., Ferguson-Smith, A., Cockett, N., et al. (2005). RNAi-mediated allelic trans-interaction at the imprinted Rtl1/Peg11 locus. Curr. Biol. 15, 743-749. doi: 10.1016/j.cub.2005.02.060

De Felice, B., Guida, M., Guida, M., Coppola, C., De Mieri, G., and Cotrufo, R. (2012). A miRNA signature in leukocytes from sporadic amyotrophic lateral sclerosis. Gene 508, 35-40. doi: 10.1016/j.gene.2012.07.058

Delay, C., Calon, F., Mathews, P., and Hebert, S. S. (2011). Alzheimer-specific variants in the 3'UTR of Amyloid precursor protein affect microRNA function. Mol. Neurodegener. 6, 70. doi: 10.1186/1750-1326-6-70

Dickson, J. R., Kruse, C., Montagna, D. R., Finsen, B., and Wolfe, M. S. (2013). Alternative polyadenylation and miR-34 family members regulate tau expression. J. Neurochem. 127, 739-749. doi: 10.1111/jnc.12437

Donev, R., Newall, A., Thome, J., and Sheer, D. (2007). A role for SC35 and hnRNPAl in the determination of amyloid precursor protein isoforms. Mol. Psychiatry 12, 681-690. doi: 10.1038/sj.mp.4001971

Doxakis, E. (2010). Post-transcriptional regulation of alpha-synuclein expression by mir-7 and mir-153. J. Biol. Chem. 285, 12726-12734. doi: 10.1074/jbc.M109.086827

Dreyfuss, G., Kim, V. N., and Kataoka, N. (2002). Messenger-RNA-binding proteins and the messages they carry. Nat. Rev. Mol. Cell Biol. 3, 195-205. doi: $10.1038 / \mathrm{nrm} 760$

Drubin, D. G., and Kirschner, M. W. (1986). Tau protein function in living cells. J. Cell Biol. 103, 2739-2746. doi: 10.1083/jcb.103.6.2739

Ebert, M. S., Neilson, J. R., and Sharp, P. A. (2007). MicroRNA sponges: competitive inhibitors of small RNAs in mammalian cells. Nat. Methods 4, 721-726. doi: 10.1038/nmeth1079

Eisenberg, I., Alexander, M. S., and Kunkel, L. M. (2009). miRNAS in normal and diseased skeletal muscle. J. Cell. Mol. Med. 13, 2-11. doi: 10.1111/j.15824934.2008.00524.x
Elbashir, S. M., Lendeckel, W., and Tuschl, T. (2001a). RNA interference is mediated by 21- and 22-nucleotide RNAs. Genes Dev. 15, 188-200. doi: $10.1101 /$ gad.862301

Elbashir, S. M., Martinez, J., Patkaniowska, A., Lendeckel, W., and Tuschl, T. (2001b). Functional anatomy of siRNAs for mediating efficient RNAi in Drosophila melanogaster embryo lysate. EMBO J. 20, 6877-6888. doi: 10.1093/emboj/20.23.6877

Espinoza, C. A., Allen, T. A., Hieb, A. R., Kugel, J. F., and Goodrich, J. A. (2004). B2 RNA binds directly to RNA polymerase II to repress transcript synthesis. Nat. Struct. Mol. Biol. 11, 822-829. doi: 10.1038/nsmb812

Fang, M., Wang, J., Zhang, X., Geng, Y., Hu, Z., Rudd, J. A., et al. (2012). The miR-124 regulates the expression of BACE1/beta-secretase correlated with cell death in Alzheimer's disease. Toxicol. Lett. 209, 94-105. doi: 10.1016/j.toxlet.2011.11.032

Fejes-Toth, K., Sotirova, V., Sachidanandam R., Assaf, G., Hannon, G., and Kapranov, P. (2009). Post-transcriptional processing generates a diversity of 5'-modified long and short RNAs. Nature 457, 1028-1032. doi: 10.1038 /nature07759

Feng, J., Bi, C., Clark, B. S., Mady, R., Shah, P., and Kohtz, J. D. (2006). The Evf2 noncoding RNA is transcribed from the Dlx-5/6 ultraconserved region and functions as a Dlx-2 transcriptional coactivator. Genes Dev. 20, 1470-1484. doi: 10.1101/gad.1416106

Figlewicz, D. A., Krizus, A., Martinoli, M. G., Meininger, V., Dib, M., Rouleau, G. A., et al. (1994). Variants of the heavy neurofilament subunit are associated with the development of amyotrophic lateral sclerosis. Hum. Mol. Genet. 3, 1757-1761. doi: 10.1093/hmg/3.10.1757

Flannery, S., and Bowie, A. G. (2010). The interleukin-1 receptor-associated kinases: critical regulators of innate immune signalling. Biochem. Pharmacol. 80, 1981-1991. doi: 10.1016/j.bcp.2010.06.020

Fox, M. A., Sanes, J. R., Borza, D. B., Eswarakumar, V. P., Fassler, R., Hudson, B. G., et al. (2007). Distinct target-derived signals organize formation, maturation, and maintenance of motor nerve terminals. Cell 129, 179-193. doi: 10.1016/j.cell.2007.02.035

Franco-Zorrilla, J. M., Valli, A., Todesco, M., Mateos, I., Puga, M. I., Rubio-Somoza, I., et al. (2007). Target mimicry provides a new mechanism for regulation of microRNA activity. Nat Genet. 39, 1033-1037. doi: 10.1038/ng2079

Galter, D., Westerlund, M., Carmine, A., Lindqvist, E., Sydow, O., and Olson, L. (2006). LRRK2 expression linked to dopamine-innervated areas. Ann. Neurol. 59, 714-719. doi: 10.1002/ana.20808

Gaughwin, P. M., Ciesla, M., Lahiri, N., Tabrizi, S. J., Brundin, P., and Bjorkqvist, M. (2011). Hsa-miR-34b is a plasma-stable microRNA that is elevated in pre-manifest Huntington's disease. Hum. Mol. Genet. 20, 2225-2237. doi: 10.1093/hmg/ddr111

Geekiyanage, H., and Chan, C. (2011). MicroRNA-137/181c regulates serine palmitoyltransferase and in turn amyloid beta, novel targets in sporadic Alzheimer's disease. J. Neurosci. 31, 14820-14830. doi: 10.1523/JNEUROSCI.3883-11.2011

Gehrke, S., Imai, Y., Sokol, N., and Lu, B. (2010). Pathogenic LRRK2 negatively regulates microRNA-mediated translational repression. Nature 466, 637-641. doi: 10.1038/nature09191

Giordana, M. T., Piccinini, M., Grifoni, S., De Marco, G., Vercellino, M., Magistrello, M., et al. (2010). TDP-43 redistribution is an early event in sporadic amyotrophic lateral sclerosis. Brain Pathol. 20, 351-360. doi: 10.1111/j.17503639.2009.00284.x

Golde, T. E., Estus, S., Usiak, M., Younkin, L. H., and Younkin, S. G. (1990). Expression of beta amyloid protein precursor mRNAs: recognition of a novel alternatively spliced form and quantitation in Alzheimer's disease using PCR. Neuron 4, 253-267. doi: 10.1016/0896-6273(90)90100-T

Gregory, R. I., Yan, K. P., Amuthan, G., Chendrimada, T., Doratotaj, B., Cooch, N., et al. (2004). The Microprocessor complex mediates the genesis of microRNAs. Nature 432, 235-240. doi: 10.1038/nature03120

Hammond, S. M., Bernstein, E., Beach, D., and Hannon, G. J. (2000). An RNAdirected nuclease mediates post-transcriptional gene silencing in Drosophila cells. Nature 404, 293-296. doi: 10.1038/35005107

Hanger, D. P., and Noble, W. (2011). Functional implications of glycogen synthase kinase-3-mediated tau phosphorylation. Int. J. Alzheimers Dis. 2011, 352805. doi: 10.4061/2011/352805

Hannun, Y. A., and Obeid, L. M. (2008). Principles of bioactive lipid signalling: lessons from sphingolipids. Nat. Rev. Mol. Cell Biol. 9, 139-150. doi: $10.1038 / \mathrm{nrm} 2329$ 
Haramati, S., Chapnik, E., Sztainberg, Y., Eilam, R., Zwang, R., Gershoni, N., et al. (2010). miRNA malfunction causes spinal motor neuron disease. Proc. Natl. Acad. Sci. U.S.A. 107, 13111-13116. doi: 10.1073/pnas.1006151107

Harper, S. Q., Staber, P. D., He, X., Eliason, S. L., Martins, I. H., Mao, Q., et al. (2005). RNA interference improves motor and neuropathological abnormalities in a Huntington's disease mouse model. Proc. Natl. Acad. Sci. U.S.A. 102, 5820-5825. doi: 10.1073/pnas.0501507102

Hass, M. R., Sato, C., Kopan, R., and Zhao, G. (2009). Presenilin: RIP and beyond. Semin. Cell Dev. Biol. 20, 201-210. doi: 10.1016/j.semcdb.2008.11.014

Hebert, S. S., and De Strooper, B. (2007). Molecular biology. miRNAs in neurodegeneration. Science 317, 1179-1180. doi: 10.1126/science.1148530

Hebert, S. S., and De Strooper, B. (2009). Alterations of the microRNA network cause neurodegenerative disease. Trends Neurosci. 32, 199-206. doi: 10.1016/j.tins.2008.12.003

Hebert, S. S., Horre, K., Nicolai, L., Papadopoulou, A. S., Mandemakers, W., Silahtaroglu, A. N., et al. (2008). Loss of microRNA cluster miR-29a/b1 in sporadic Alzheimer's disease correlates with increased BACE1/betasecretase expression. Proc. Natl. Acad. Sci. U.S.A. 105, 6415-6420. doi: 10.1073/pnas.0710263105

Hellwig, S., and Bass, B. L. (2008) A starvation-induced noncoding RNA modulates expression of Dicer-regulated genes. Proc. Natl. Acad. Sci. U.S.A. 105, 12897-12902 doi: 10.1073/pnas.0805118105

Hong, M., and Lee, V. M. (1997). Insulin and insulin-like growth factor-1 regulate tau phosphorylation in cultured human neurons. J. Biol. Chem. 272, 19547-19553. doi: 10.1074/jbc.272.31.19547

Hu, Y. K., Wang, X., Li, L., Du, Y. H., Ye, H. T., and Li, C. Y. (2013). MicroRNA-98 induces an Alzheimer's disease-like disturbance by targeting insulin-like growth factor 1. Neurosci. Bull. 29, 745-751. doi: 10.1007/s12264-013-1348-5

Hunter, C., and Poethig, R. S. (2003). miSSING LINKS: miRNAs and plant development. Curr. Opin. Genet. Dev. 13, 372-378. doi: 10.1016/S0959-437X(03) 00081-9

Ittner, L. M., Ke, Y. D., Delerue, F., Bi, M., Gladbach, A., Van Eersel, J., et al. (2010). Dendritic function of tau mediates amyloid-beta toxicity in Alzheimer's disease mouse models. Cell 142, 387-397. doi: 10.1016/j.cell.2010.06.036

Jacobsen, J. S., Blume, A. J., and Vitek, M. P. (1991). Quantitative measurement of alternatively spliced amyloid precursor protein mRNA expression in Alzheimer's disease and normal brain by $\mathrm{S} 1$ nuclease protection analysis. Neurobiol. Aging 12, 585-592. doi: 10.1016/0197-4580(91)90090-7

Jakes, R., Spillantini, M. G., and Goedert, M. (1994). Identification of two distinct synucleins from human brain. FEBS Lett. 345, 27-32. doi: 10.1016/00145793(94)00395-5

Jayadev, S., Case, A., Alajajian, B., Eastman, A. J., Moller, T., and Garden, G. A. (2013). Presenilin 2 influences miR146 level and activity in microglia. J. Neurochem. 127, 592-599. doi: 10.1111/jnc.12400

Jayadev, S., Case, A., Eastman, A. J., Nguyen, H., Pollak, J., Wiley, J. C., et al. (2010). Presenilin 2 is the predominant gamma-secretase in microglia and modulates cytokine release. PLoS ONE 5:e15743. doi: 10.1371/journal.pone.0015743

Jere, D., Arote, R., Jiang, H. L., Kim, Y. K., Cho, M. H., and Cho, C. S. (2009). Bioreducible polymers for efficient gene and siRNA delivery. Biomed. Mater. 4:025020. doi: 10.1088/1748-6041/4/2/025020

Johnson, R. and Bucley, N. J. (2009a). Gene dysregulation in Huntington's disease: REST, microRNAs and beyond. Neuromolecular Med. 11, 183-99. doi: 10.1007/s12017-009-8063-4

Johnson, R., Teh CH., Jia H., Vanisri RR., Pandey T., Lu ZH., et al. (2009b) Regulation of neural macroRNAs by the transcriptional repressor REST. RNA 15, 85-96. doi: 10.1261/rna.1127009

Johnson, R., Noble, W., Tartaglia, G. G., and Buckley, N. J. (2012). Neurodegeneration as an RNA disorder. Prog. Neurobiol. 99, 293-315. doi: 10.1016/j.pneurobio.2012.09.006

Johnson, R., Zuccato, C., Belyaev, N. D., Guest, D. J., Cattaneo, E., and Buckley, N. J. (2008). A microRNA-based gene dysregulation pathway in Huntington's disease. Neurobiol. Dis. 29, 438-445. doi: 10.1016/j.nbd.2007.11.001

Juliano, R., Alam, M. R., Dixit, V., and Kang, H. (2008). Mechanisms and strategies for effective delivery of antisense and siRNA oligonucleotides. Nucleic Acids Res. 36, 4158-4171. doi: 10.1093/nar/gkn342

Juliano, R. L. (2005). Peptide-oligonucleotide conjugates for the delivery of antisense and siRNA. Curr. Opin. Mol. Ther. 7, 132-136.

Julien, J. P. (1999). Neurofilament functions in health and disease. Curr. Opin. Neurobiol. 9, 554-560. doi: 10.1016/S0959-4388(99)00004-5
Junn, E., Lee, K. W., Jeong, B. S., Chan, T. W., Im, J. Y., and Mouradian, M. M. (2009). Repression of alpha-synuclein expression and toxicity by microRNA-7. Proc. Natl. Acad. Sci. U.S.A. 106, 13052-13057. doi: 10.1073/pnas. 0906277106

Kabashi, E., Valdmanis, P. N., Dion, P., Spiegelman, D., Mcconkey, B. J., Vande Velde, C., et al. (2008). TARDBP mutations in individuals with sporadic and familial amyotrophic lateral sclerosis. Nat. Genet. 40, 572-574. doi: 10.1038/ng.132

Kapranov, P., Cheng, J., Dike, S., Nix, D. A., Duttagupta, R., Willingham, A. T., et al. (2007). RNA maps reveal new RNA classes and a possible function for pervasive transcription. Science 316, 1484-1488. doi: 10.1126/science. 1138341

Kelly, T. K., De Carvalho, D. D., and Jones, P. A. (2010). Epigenetic modifications as therapeutic targets. Nat. Biotechnol. 28, 1069-1078. doi: 10.1038/ nbt. 1678

Kiernan, M. C., Vucic, S., Cheah, B. C., Turner, M. R., Eisen, A., Hardiman, O., et al. (2011). Amyotrophic lateral sclerosis. Lancet 377, 942-955. doi: 10.1016/S01406736(10)61156-7

Kim, D. H., and Rossi, J. J. (2007). Strategies for silencing human disease using RNA interference. Nat. Rev. Genet. 8, 173-184. doi: 10.1038/nrg2006

Kim, J., Inoue, K., Ishii, J., Vanti, W. B., Voronov, S. V., Murchison, E., et al. (2007). A MicroRNA feedback circuit in midbrain dopamine neurons. Science 317, 1220-1224. doi: 10.1126/science. 1140481

Kluiver, J., Gibcus, J. H., Hettinga, C., Adema, A., Richter, M. K., Halsema, N., et al. (2012a). Rapid generation of microRNA sponges for microRNA inhibition. PLoS ONE 7:e29275. doi: 10.1371/journal.pone.0029275

Kluiver, J., Slezak-Prochazka, I., Smigielska-Czepiel, K., Halsema, N., Kroesen, B. J., and Van Den Berg, A. (2012b). Generation of miRNA sponge constructs. Methods 58, 113-117. doi: 10.1016/j.ymeth.2012.07.019

Kohlmaier, A., Savarese, F., Lachner, M., Martens, J., Jenuwein, T., and Wutz, A. (2004). A chromosomal memory triggered by Xist regulates histone methylation in X inactivation. PLoS Biol. 2:E171. doi: 10.1371/journal.pbio.0020171

Kosik, K. S., Joachim, C. L., and Selkoe, D. J. (1986). Microtubule-associated protein tau (tau) is a major antigenic component of paired helical filaments in Alzheimer disease. Proc. Natl. Acad. Sci. U.S.A. 83, 4044-4048. doi: 10.1073/pnas.83.11.4044

Koval, E. D., Shaner, C., Zhang, P., Du Maine, X., Fischer, K., Tay, J., et al. (2013). Method for widespread microRNA-155 inhibition prolongs survival in ALS-model mice. Hum. Mol. Genet. 22, 4127-4135. doi: 10.1093/ hmg/ddt261

Krichevsky, A. M., King, K. S., Donahue, C. P., Khrapko, K., and Kosik, K. S. (2003). A microRNA array reveals extensive regulation of microRNAs during brain development. RNA 9, 1274-1281. doi: 10.1261/rna.5980303

Krutzfeldt, J., Kuwajima, S., Braich, R., Rajeev, K. G., Pena, J., Tuschl, T., et al. (2007). Specificity, duplex degradation and subcellular localization of antagomirs. Nucleic Acids Res. 35, 2885-2892. doi: 10.1093/nar/ gkm024

Krutzfeldt, J., Rajewsky, N., Braich, R., Rajeev, K. G., Tuschl, T., Manoharan, M., et al. (2005). Silencing of microRNAs in vivo with 'antagomirs'. Nature 438, 685-689. doi: 10.1038/nature04303

Kumar, P., Ban, H. S., Kim, S. S., Wu, H., Pearson, T., Greiner, D. L., et al. (2008). T cell-specific siRNA delivery suppresses HIV-1 infection in humanized mice. Cell 134, 577-586. doi: 10.1016/j.cell.2008.06.034

Kwiatkowski, T. J., Jr., Bosco, D. A., Leclerc, A. L., Tamrazian, E., Vanderburg, C. R., Russ, C., et al. (2009). Mutations in the FUS/TLS gene on chromosome 16 cause familial amyotrophic lateral sclerosis. Science 323, 1205-1208. doi: 10.1126/science.1166066

Lagier-Tourenne, C., Polymenidou, M., and Cleveland, D. W. (2010). TDP-43 and FUS/TLS: emerging roles in RNA processing and neurodegeneration. Hum. Mol. Genet. 19, R46-R64. doi: 10.1093/hmg/ddq137

Lagos-Quintana, M., Rauhut, R., Lendeckel, W., and Tuschl, T. (2001). Identification of novel genes coding for small expressed RNAs. Science 294, 853-858. doi: 10.1126/science.1064921

Lagos-Quintana, M., Rauhut, R., Yalcin, A., Meyer, J., Lendeckel, W., and Tuschl, T. (2002). Identification of tissue-specific microRNAs from mouse. Curr. Biol. 12, 735-739. doi: 10.1016/S0960-9822(02)00809-6

Landgraf, P., Rusu, M., Sheridan, R., Sewer, A., Iovino, N., Aravin, A., et al. (2007). A mammalian microRNA expression atlas based on small RNA library sequencing. Cell 129, 1401-1414. doi: 10.1016/j.cell. 2007.04.040 
Lau, N. C., Lim, L. P., Weinstein, E. G., and Bartel, D. P. (2001). An abundant class of tiny RNAs with probable regulatory roles in Caenorhabditis elegans. Science 294, 858-862. doi: 10.1126/science.1065062

Lee, R. C., Feinbaum, R. L., and Ambros, V. (1993). The C. elegans heterochronic gene lin-4 encodes small RNAs with antisense complementarity to lin-14. Cell 75, 843-854. doi: 10.1016/0092-8674(93)90529-Y

Lee, S. J., Liyanage, U., Bickel, P. E., Xia, W., Lansbury, P. T. Jr., and Kosik, K. S. (1998). A detergent-insoluble membrane compartment contains A beta in vivo. Nat. Med. 4, 730-734. doi: 10.1038/nm0698-730

Lee, V. M., Goedert, M., and Trojanowski, J. Q. (2001). Neurodegenerative tauopathies. Annu. Rev. Neurosci. 24, 1121-1159. doi: 10.1146/annurev.neuro.24.1.1121

Li, Z., Lu, Y., Xu, X. L., and Gao, F. B. (2013). The FTD/ALS-associated RNAbinding protein TDP-43 regulates the robustness of neuronal specification through microRNA-9a in Drosophila. Hum. Mol. Genet. 22, 218-225. doi: $10.1093 / \mathrm{hmg} / \mathrm{dds} 420$

Liem, R. K., and Messing, A. (2009). Dysfunctions of neuronal and glial intermediate filaments in disease. J. Clin. Invest. 119, 1814-1824. doi: 10.1172/ JCI38003

Lin, X., Parisiadou, L., Gu, X. L., Wang, L., Shim, H., Sun, L., et al. (2009). Leucinerich repeat kinase 2 regulates the progression of neuropathology induced by Parkinson's-disease-related mutant alpha-synuclein. Neuron 64, 807-827. doi: 10.1016/j.neuron.2009.11.006

Ling, S. C., Albuquerque, C. P., Han, J. S., Lagier-Tourenne, C., Tokunaga, S., Zhou, H., et al. (2010). ALS-associated mutations in TDP-43 increase its stability and promote TDP-43 complexes with FUS/TLS. Proc. Natl. Acad. Sci. U.S.A. 107, 13318-13323. doi: 10.1073/pnas. 1008227107

Lipovich, L., Johnson, R., and Lin, C. Y. (2010). MacroRNA underdogs in a microRNA world: evolutionary, regulatory, and biomedical significance of mammalian long non-protein-coding RNA. Biochim. Biophys. Acta 1799, 597-615. doi: 10.1016/j.bbagrm.2010.10.001

Liu, H. L., Hua, M. Y., Chen, P. Y., Chu, P. C., Pan, C. H., Yang, H. W., et al. (2010). Blood-brain barrier disruption with focused ultrasound enhances delivery of chemotherapeutic drugs for glioblastoma treatment. Radiology 255, 415-425. doi: 10.1148/radiol.10090699

Long, J. M., and Lahiri, D. K. (2011). MicroRNA-101 downregulates Alzheimer's amyloid-beta precursor protein levels in human cell cultures and is differentially expressed. Biochem. Biophys. Res. Commun. 404, 889-895. doi: 10.1016/j.bbrc.2010.12.053

Lukiw, W. J. (2007). Micro-RNA speciation in fetal, adult and Alzheimer's disease hippocampus. Neuroreport 18, 297-300. doi: 10.1097/WNR.0b013e32 $80148 \mathrm{e} 8 \mathrm{~b}$

Maciotta, S., Meregalli, M., Cassinelli, L., Parolini, D., Farini, A., Fraro, G. D., et al. (2012). Hmgb3 is regulated by microRNA-206 during muscle regeneration. PLOS ONE 7:e43464. doi: 10.1371/journal.pone. 0043464

Mahato, R. I., Kawabata, K., Takakura, Y., and Hashida, M. (1995). In vivo disposition characteristics of plasmid DNA complexed with cationic liposomes. J. Drug Target. 3, 149-157. doi: 10.3109/10611869509059214

Makeyev, E. V., Zhang, J., Carrasco, M. A., and Maniatis, T. (2007). The MicroRNA miR-124 promotes neuronal differentiation by triggering brain-specific alternative pre-mRNA splicing. Mol. Cell 27, 435-448. doi: 10.1016/j.molcel.2007.07.015

Makimura, H., Mizuno, T. M., Mastaitis, J. W., Agami, R., and Mobbs, C. V. (2002). Reducing hypothalamic AGRP by RNA interference increases metabolic rate and decreases body weight without influencing food intake. BMC Neurosci. 3:18. doi: 10.1186/1471-2202-3-18

Malumbres, R., Sarosiek, K. A., Cubedo, E., Ruiz, J. W., Jiang, X., Gascoyne, R. D., et al. (2009). Differentiation stage-specific expression of microRNAs in B lymphocytes and diffuse large B-cell lymphomas. Blood 113, 3754-3764. doi: 10.1182/blood-2008-10-184077

Margis, R., Margis, R., and Rieder, C. R. (2011). Identification of blood microRNAs associated to Parkinsonis disease. J. Biotechnol. 152, 96-101. doi: 10.1016/j.jbiotec.2011.01.023

Mariner, P. D., Walters, R. D., Espinoza, C. A., Drullinger, L. F., Wagner, S. D., Kugel, J. F., et al. (2008). Human Alu RNA is a modular transacting repressor of mRNA transcription during heat shock. Mol. Cell 29, 499-509. doi: 10.1016/j.molcel.2007.12.013
Marti, E., Pantano, L., Banez-Coronel, M., Llorens, F., Minones-Moyano, E., Porta, S., et al. (2010). A myriad of miRNA variants in control and Huntington's disease brain regions detected by massively parallel sequencing. Nucleic Acids Res. 38, 7219-7235. doi: 10.1093/nar/gkq575

Martinez, J., Patkaniowska, A., Urlaub, H., Luhrmann, R., and Tuschl, T. (2002). Single-stranded antisense siRNAs guide target RNA cleavage in RNAi. Cell 110, 563-574. doi: 10.1016/S0092-8674(02) 00908-X

Masliah, E., Rockenstein, E., Veinbergs, I., Mallory, M., Hashimoto, M., Takeda, A., et al. (2000). Dopaminergic loss and inclusion body formation in alpha-synuclein mice: implications for neurodegenerative disorders. Science 287, 1265-1269. doi: 10.1126/science.287. 5456.1265

Matkovich, S. J., Van Booven, D. J., Youker, K. A., Torre-Amione, G., Diwan, A., Eschenbacher, W. H., et al. (2009). Reciprocal regulation of myocardial microRNAs and messenger RNA in human cardiomyopathy and reversal of the microRNA signature by biomechanical support. Circulation 119, 1263-1271. doi: 10.1161/CIRCULATIONAHA.108.813576

Mckhann, G., Drachman, D., Folstein, M., Katzman, R., Price, D., and Stadlan, E. M. (1984). Clinical diagnosis of Alzheimer's disease: report of the NINCDSADRDA Work Group under the auspices of Department of Health and Human Services Task Force on Alzheimer's Disease. Neurology 34, 939-944. doi: 10.1212/WNL.34.7.939

Melrose, H., Lincoln, S., Tyndall, G., Dickson, D., and Farrer, M. (2006). Anatomical localization of leucine-rich repeat kinase 2 in mouse brain. Neuroscience 139, 791-794. doi: 10.1016/j.neuroscience.2006. 01.017

Minones-Moyano, E., Porta, S., Escaramis, G., Rabionet, R., Iraola, S., Kagerbauer, B., et al. (2011). MicroRNA profiling of Parkinson's disease brains identifies early downregulation of $\mathrm{miR}-34 \mathrm{~b} / \mathrm{c}$ which modulate mitochondrial function. Hum. Mol. Genet. 20, 3067-3078. doi: 10.1093/hmg/ddr210

Mori, F., Anji, K., Oshimoto, M., Akahashi, H., and Wakabayashi, K. (2002). Demonstration of alpha-synuclein immunoreactivity in neuronal and glial cytoplasm in normal human brain tissue using proteinase $\mathrm{K}$ and formic acid pretreatment. Exp. Neurol. 176, 98-104. doi: 10.1006/exnr. 2002.7929

Morlando, M., Dini Modigliani, S., Torrelli, G., Rosa, A., Di Carlo, V., Caffarelli, E., et al. (2012). FUS stimulates microRNA biogenesis by facilitating co-transcriptional Drosha recruitment. EMBO J. 31, 4502-4510. doi: 10.1038/emboj.2012.319

Mouradian, M. M. (2012). MicroRNAs in Parkinson's disease. Neurobiol. Dis. 46, 279-284. doi: 10.1016/j.nbd.2011.12.046

Mucke, L., and Selkoe, D. J. (2011). Neurotoxicity of amyloid beta-protein: synaptic and network dysfunction. Cold Spring Harb. Perspect. Med. 2:a006338. doi: 10.1101/cshperspect.a006338

Neve, R. L., Rogers, J., and Higgins, G. A. (1990). The Alzheimer amyloid precursor-related transcript lacking the beta/A4 sequence is specifically increased in Alzheimer's disease brain. Neuron 5, 329-338. doi: 10.1016/08966273(90)90169-G

Ningaraj, N. S., Salimath, B. P., Sankpal, U. T., Perera, R., and Vats, T. (2007). Targeted brain tumor treatment-current perspectives. Drug Target Insights 2, 197-207.

Nukina, N., and Ihara, Y. (1986). One of the antigenic determinants of paired helical filaments is related to tau protein. J. Biochem. 99, 1541-1544.

Nunez-Iglesias, J., Liu, C. C., Morgan, T. E., Finch, C. E., and Zhou, X. J. (2010). Joint genome-wide profiling of miRNA and mRNA expression in Alzheimer's disease cortex reveals altered miRNA regulation. PLOS ONE 5:e8898. doi: 10.1371/journal.pone.0008898

Nykanen, A., Haley, B., and Zamore, P. D. (2001). ATP requirements and small interfering RNA structure in the RNA interference pathway. Cell 107, 309-321. doi: 10.1016/S0092-8674(01)00547-5

Ohmachi, S., Mikami, T., Konishi, M., Miyake, A., and Itoh, N. (2003). Preferential neurotrophic activity of fibroblast growth factor-20 for dopaminergic neurons through fibroblast growth factor receptor-1c. J. Neurosci. Res. 72, 436-443. doi: 10.1002/jnr. 10592

Ohmachi, S., Watanabe, Y., Mikami, T., Kusu, N., Ibi, T., Akaike, A., et al. (2000). FGF-20, a novel neurotrophic factor, preferentially expressed in the substantia nigra pars compacta of rat brain. Biochem. Biophys. Res. Commun. 277, 355-360. doi: $10.1006 /$ bbrc. 2000.3675 
Ooi, L., and Wood, I. C. (2007). Chromatin crosstalk in development and disease: lessons from REST. Nat. Rev. Genet. 8, 544-554. doi: 10.1038/ nrg2 100

Packer, A. N., Xing, Y., Harper, S. Q., Jones, L., and Davidson, B. L. (2008). The bifunctional microRNA miR-9/miR-9* regulates REST and CoREST and is downregulated in Huntington's disease. J. Neurosci. 28, 14341-14346. doi: 10.1523/JNEUROSCI.2390-08.2008

Palm, T., Bahnassawy, L., and Schwamborn, J. (2012). MiRNAs and neural stem cells: a team to treat Parkinson's disease? RNA Biol. 9, 720-730. doi: 10.4161/rna.19984

Palop, J. J., and Mucke, L. (2010). Amyloid-beta-induced neuronal dysfunction in Alzheimer's disease: from synapses toward neural networks. Nat. Neurosci. 13, 812-818. doi: 10.1038/nn.2583

Papagiannakopoulos, T., and Kosik, K. S. (2009). MicroRNA-124: micromanager of neurogenesis. Cell Stem Cell 4, 375-376. doi: 10.1016/j.stem.2009. 04.007

Pardridge, W. M. (2007). shRNA and siRNA delivery to the brain. Adv. Drug Deliv. Rev. 59, 141-152. doi: 10.1016/j.addr.2007.03.008

Parisiadou, L., Xie, C., Cho, H. J., Lin, X., Gu, X. L., Long, C. X., et al. (2009). Phosphorylation of ezrin/radixin/moesin proteins by LRRK2 promotes the rearrangement of actin cytoskeleton in neuronal morphogenesis. J. Neurosci. 29, 13971-13980. doi: 10.1523/JNEUROSCI.3799-09.2009

Pasquinelli, A. E., Reinhart, B. J., Slack, F., Martindale, M. Q., Kuroda, M. I., Maller, B., et al. (2000). Conservation of the sequence and temporal expression of let-7 heterochronic regulatory RNA. Nature 408, 86-89. doi: 10.1038/35040556

Patel, N., Hoang, D., Miller, N., Ansaloni, S., Huang, Q., Rogers, J. T., et al. (2008). MicroRNAs can regulate human APP levels. Mol. Neurodegener. 3:10. doi: 10.1186/1750-1326-3-10

Pesiridis, G. S., Lee, V. M., and Trojanowski, J. Q. (2009). Mutations in TDP-43 link glycine-rich domain functions to amyotrophic lateral sclerosis. Hum. Mol. Genet. 18, R156-R162. doi: 10.1093/hmg/ddp303

Plath, K., Fang, J., Mlynarczyk-Evans, S. K., Cao, R., Worringer, K. A., Wang, H., et al. (2003). Role of histone $\mathrm{H} 3$ lysine 27 methylation in $\mathrm{X}$ inactivation. Science 300, 131-135. doi: 10.1126/science. 1084274

Ponting, C. P., Oliver, P. L., and Reik, W. (2009). Evolution and functions of long noncoding RNAs. Cell 136, 629-641. doi: 10.1016/j.cell.2009.02.006

Pushparaj, P. N., Aarthi, J. J., Manikandan, J., and Kumar, S. D. (2008). siRNA, miRNA, and shRNA: in vivo applications. J. Dent. Res. 87, 992-1003. doi: 10.1177/154405910808701109

Ralph, G. S., Radcliffe, P. A., Day, D. M., Carthy, J. M., Leroux, M. A., Lee, D. C., et al. (2005). Silencing mutant SOD1 using RNAi protects against neurodegeneration and extends survival in an ALS model. Nat. Med. 11, 429-433. doi: $10.1038 / \mathrm{nm} 1205$

Rao, P. K., Kumar, R. M., Farkhondeh, M., Baskerville, S., and Lodish, H. F. (2006). Myogenic factors that regulate expression of muscle-specific microRNAs. Proc. Natl. Acad. Sci. U.S.A. 103, 8721-8726. doi: 10.1073/pnas.0602831103

Rapoport, M., Dawson, H. N., Binder, L. I., Vitek, M. P., and Ferreira, A. (2002). Tau is essential to beta -amyloid-induced neurotoxicity. Proc. Natl. Acad. Sci. U.S.A. 99, 6364-6369. doi: 10.1073/pnas.092136199

Reinhart, B. J., and Bartel, D. P. (2002). Small RNAs correspond to centromere heterochromatic repeats. Science 297, 1831. doi: 10.1126/science.1077183

Roberson, E. D., Scearce-Levie, K., Palop, J. J., Yan, F., Cheng, I. H., Wu, T., et al. (2007). Reducing endogenous tau ameliorates amyloid beta-induced deficits in an Alzheimer's disease mouse model. Science 316, 750-754. doi: $10.1126 /$ science. 1141736

Rockenstein, E. M., Mcconlogue, L., Tan, H., Power, M., Masliah, E., and Mucke, L. (1995). Levels and alternative splicing of amyloid beta protein precursor (APP) transcripts in brains of APP transgenic mice and humans with Alzheimer's disease. J. Biol. Chem. 270, 28257-28267. doi: 10.1074/jbc. 270.47.28257

Rosario, P. W. (2010). Normal values of serum IGF-1 in adults: results from a Brazilian population. Arq. Bras. Endocrinol. Metabol. 54, 477-481. doi: 10.1590/S0004-27302010000500008

Saido, T., and Leissring, M. A. (2012). Proteolytic degradation of amyloid betaprotein. Cold Spring Harb. Perspect. Med. 2:a006379. doi: 10.1101/cshperspect.a006379

Saiki, S., Sato, S., and Hattori, N. (2011). Molecular pathogenesis of Parkinson's disease: update. J. Neurol. Neurosurg. Psychiatry 83, 430-436. doi: 10.1136/jnnp2011-301205
Satake, W., Nakabayashi, Y., Mizuta, I., Hirota, Y., Ito, C., Kubo, M., et al. (2009). Genome-wide association study identifies common variants at four loci as genetic risk factors for Parkinson's disease. Nat. Genet. 41, 1303-1307. doi: 10.1038/ng.485

Savas, J. N., Makusky, A., Ottosen, S., Baillat, D., Then, F., Krainc, D., et al. (2008). Huntington's disease protein contributes to RNA-mediated gene silencing through association with Argonaute and P bodies. Proc. Natl. Acad. Sci. U.S.A. 105, 10820-10825. doi: 10.1073/pnas.0800658105

Schenk, D., Basi, G. S., and Pangalos, M. N. (2012). Treatment strategies targeting amyloid beta-protein. Cold Spring Harb. Perspect. Med. 2:a006387. doi: 10.1101/cshperspect.a006387

Schipper, H. M., Maes, O. C., Chertkow, H. M., and Wang, E. (2007). MicroRNA expression in Alzheimer blood mononuclear cells. Gene Regul. Syst. Biol. 1, 263-274.

Schwarz, D. S., Hutvagner, G., Haley, B., and Zamore, P. D. (2002). Evidence that siRNAs function as guides, not primers, in the Drosophila and human RNAi pathways. Mol. Cell 10, 537-548. doi: 10.1016/S1097-2765(02) 00651-2

Sempere, L. F., Freemantle, S., Pitha-Rowe, I., Moss, E., Dmitrovsky, E., and Ambros, V. (2004). Expression profiling of mammalian microRNAs uncovers a subset of brain-expressed microRNAs with possible roles in murine and human neuronal differentiation. Genome Biol. 5:R13. doi: 10.1186/gb-2004-5-3-r13

Shamovsky, I., Ivannikov, M., Kandel, E. S., Gershon, D., and Nudler, E. (2006). RNA-mediated response to heat shock in mammalian cells. Nature 440, 556-560. doi: 10.1038/nature04518

Shen, Y. (2008). Advances in the development of siRNA-based therapeutics for cancer. IDrugs 11, 572-578.

Shioya, M., Obayashi, S., Tabunoki, H., Arima, K., Saito, Y., Ishida, T., et al. (2010). Aberrant microRNA expression in the brains of neurodegenerative diseases: miR-29a decreased in Alzheimer disease brains targets neurone navigator 3. Neuropathol. Appl. Neurobiol. 36, 320-330. doi: 10.1111/j.13652990.2010.01076.x

Shtilbans, A., and Henchcliffe, C. (2012). Biomarkers in Parkinson's disease: an update. Curr. Opin. Neurol. 25, 460-465. doi: 10.1097/WCO.0b013e32 83550c0d

Silva, J., Mak, W., Zvetkova, I., Appanah, R., Nesterova, T. B., Webster, Z., et al. (2003). Establishment of histone h3 methylation on the inactive X chromosome requires transient recruitment of Eed-Enxl polycomb group complexes. Dev. Cell 4, 481-495. doi: 10.1016/S1534-5807(03)00068-6

Simon-Sanchez, J., Schulte, C., Bras, J. M., Sharma, M., Gibbs, J. R., Berg, D., et al. (2009). Genome-wide association study reveals genetic risk underlying Parkinson's disease. Nat. Genet. 41, 1308-1312. doi: 10.1038/ng.487

Singleton, A. B., Farrer, M., Johnson, J., Singleton, A., Hague, S., Kachergus, J., et al. (2003). alpha-Synuclein locus triplication causes Parkinson's disease. Science 302, 841. doi: 10.1126/science. 1090278

Sinha, M., Mukhopadhyay, S., and Bhattacharyya, N. P. (2012). Mechanism(s) of alteration of micro RNA expressions in Huntington's disease and their possible contributions to the observed cellular and molecular dysfunctions in the disease. Neuromolecular Med. 14, 221-243. doi: 10.1007/s12017-012-8183-0

Skog, J., Wurdinger, T., Van Rijn, S., Meijer, D. H., Gainche, L., Sena-Esteves, M., et al. (2008). Glioblastoma microvesicles transport RNA and proteins that promote tumour growth and provide diagnostic biomarkers. Nat. Cell Biol. 10, 1470-1476. doi: 10.1038/ncb1800

Smirnova, L., Grafe, A., Seiler, A., Schumacher, S., Nitsch, R., and Wulczyn, F. G. (2005). Regulation of miRNA expression during neural cell specification. Eur. J. Neurosci. 21, 1469-1477. doi: 10.1111/j.1460-9568.2005.03978.x

Smith, P., Al Hashimi, A., Girard, J., Delay, C., and Hebert, S. S. (2011). In vivo regulation of amyloid precursor protein neuronal splicing by microRNAs. J. Neurochem. 116, 240-247. doi: 10.1111/j.1471-4159.2010.07097.x

Sotiriou, S. Gibney G., Baxevanis AD., and Nussbaum RL. (2009) A single nucleotide polymorphism in the 3'UTR of SNCA gene encoding alphasynuclein is a new potential susceptibility locus for Parkinson's Disease. Neurosci. Lett. 461, 196-201 doi: 10.1016/j.neulet.2009.06.034

Sreedharan, J., Blair, I. P., Tripathi, V. B., Hu, X., Vance, C., Rogelj, B., et al. (2008). TDP-43 mutations in familial and sporadic amyotrophic lateral sclerosis. Science 319, 1668-1672. doi: 10.1126/science.1154584

Subramanian, S., Lui, W. O., Lee, C. H., Espinosa, I., Nielsen, T. O., Heinrich, M. C., et al. (2008). MicroRNA expression signature of human sarcomas. Oncogene 27, 2015-2026. doi: 10.1038/sj.onc.1210836 
Sugars, K. L., and Rubinsztein, D. C. (2003). Transcriptional abnormalities in Huntington disease. Trends Genet. 19, 233-238. doi: 10.1016/S01689525(03)00074-X

Suzuki, H. I., Yamagata, K., Sugimoto, K., Iwamoto, T., Kato, S., and Miyazono, K. (2009). Modulation of microRNA processing by p53. Nature 460, 529-533. doi: 10.1038 /nature08199

Swantek, J. L., Tsen, M. F., Cobb, M. H., and Thomas, J. A. (2000). IL-1 receptorassociated kinase modulates host responsiveness to endotoxin. J. Immunol. 164, 430-436.

Tan, E. K., and Skipper, L. M. (2007). Pathogenic mutations in Parkinson disease. Hum. Mutat. 28, 641-653. doi: 10.1002/humu.20507

Tanzi, R., Gaston, S., Bush, A., Romano, D., Pettingell, W., Peppercorn, J., et al. (1993). Genetic heterogeneity of gene defects responsible for familial Alzheimer disease. Genetica 91, 255-263. doi: 10.1007/BF01436002

Thum, T., Gross, C., Fiedler, J., Fischer, T., Kissler, S., Bussen, M., et al. (2008). MicroRNA-21 contributes to myocardial disease by stimulating MAP kinase signalling in fibroblasts. Nature 456, 980-984. doi: 10.1038/ nature 07511

Tomkins, J., Usher, P., Slade, J. Y., Ince, P. G., Curtis, A., Bushby, K., et al. (1998). Novel insertion in the KSP region of the neurofilament heavy gene in amyotrophic lateral sclerosis (ALS). Neuroreport 9, 3967-3970. doi: 10.1097/00001756-199812010-00036

Uyechi, L. S., Gagne, L., Thurston, G., and Szoka, F. C. Jr. (2001). Mechanism of lipoplex gene delivery in mouse lung: binding and internalization of fluorescent lipid and DNA components. Gene Ther. 8, 828-836. doi: 10.1038/sj.gt.3301461

Valadi, H., Ekstrom, K., Bossios, A., Sjostrand, M., Lee, J. J., and Lotvall, J. O. (2007). Exosome-mediated transfer of mRNAs and microRNAs is a novel mechanism of genetic exchange between cells. Nat. Cell Biol. 9, 654-659. doi: $10.1038 /$ ncb 1596

Vance, C., Rogelj, B., Hortobagyi, T., De Vos, K. J., Nishimura, A. L., Sreedharan, J., et al. (2009). Mutations in FUS, an RNA processing protein, cause familial amyotrophic lateral sclerosis type 6 . Science 323, 1208-1211. doi: 10.1126/science. 1165942

Van Rooij, E., and Olson, E. N. (2007). MicroRNAs: powerful new regulators of heart disease and provocative therapeutic targets. J. Clin. Invest. 117, 2369-2376. doi: 10.1172/JCI33099

Vargas, T., Martinez-Garcia, A., Antequera, D., Vilella, E., Clarimon, J., Mateo, I., et al. (2011). IGF-I gene variability is associated with an increased risk for AD. Neurobiol. Aging 32, 556 e553-e511. doi: 10.1016/j.neurobiolaging.2010.10.017

Vetrivel, K. S., Cheng, H., Kim, S. H., Chen, Y., Barnes, N. Y., Parent, A. T., et al. (2005). Spatial segregation of gamma-secretase and substrates in distinct membrane domains. J. Biol. Chem. 280, 25892-25900. doi: 10.1074/jbc.M503570200

Vilardo, E., Barbato, C., Ciotti, M., Cogoni, C., and Ruberti, F. (2010). MicroRNA101 regulates amyloid precursor protein expression in hippocampal neurons. J. Biol. Chem. 285, 18344-18351. doi: 10.1074/jbc.M110.112664

Vossel, K. A., Zhang, K., Brodbeck, J., Daub, A. C., Sharma, P., Finkbeiner, S., et al. (2010). Tau reduction prevents Abeta-induced defects in axonal transport. Science 330, 198. doi: 10.1126/science.1194653

Wang, D., Lu, M., Miao, J., Li, T., Wang, E., and Cui, Q. (2009). Cepred: predicting the co-expression patterns of the human intronic microRNAs with their host genes. PLoS ONE 4:e4421. doi: 10.1371/journal.pone.0004421

Wang, G., Van Der Walt, J. M., Mayhew, G., Li, Y. J., Zuchner, S., Scott, W. K., et al. (2008a). Variation in the miRNA-433 binding site of FGF20 confers risk for Parkinson disease by overexpression of alpha-synuclein. Am. J. Hum. Genet. 82, 283-289. doi: 10.1016/j.ajhg.2007.09.021

Wang, W. X., Rajeev, B. W., Stromberg, A. J., Ren, N., Tang, G., Huang, Q., et al. (2008b). The expression of microRNA miR-107 decreases early in Alzheimer's disease and may accelerate disease progression through regulation of beta-site amyloid precursor protein-cleaving enzyme 1. J. Neurosci. 28, 1213-1223. doi: 10.1523/JNEUROSCI.5065-07.2008

Wang, J., Zhang, P. C., Lu, H. F., Ma, N., Wang, S., Mao, H. Q., et al. (2002). New polyphosphoramidate with a spermidine side chain as a gene carrier. J. Control. Release 83, 157-168. doi: 10.1016/S0168-3659(02)00180-3

Weingarten, M. D., Lockwood, A. H., Hwo, S. Y., and Kirschner, M. W. (1975). A protein factor essential for microtubule assembly. Proc. Natl. Acad. Sci. U.S.A. 72, 1858-1862. doi: 10.1073/pnas.72.5.1858
Whitehead, K. A., Langer, R., and Anderson, D. G. (2009). Knocking down barriers: advances in siRNA delivery. Nat. Rev. Drug Discov. 8, 129-138. doi: $10.1038 / \mathrm{nrd} 2742$

Williams, A. H., Valdez, G., Moresi, V., Qi, X., Mcanally, J., Elliott, J. L., et al. (2009). MicroRNA-206 delays ALS progression and promotes regeneration of neuromuscular synapses in mice. Science 326, 1549-1554. doi: 10.1126/science. 1181046

Wislet-Gendebien, S., Visanji, N. P., Whitehead, S. N., Marsilio, D., Hou, W., Figeys, D., et al. (2008). Differential regulation of wild-type and mutant alphasynuclein binding to synaptic membranes by cytosolic factors. BMC Neurosci. 9:92. doi: 10.1186/1471-2202-9-92

Wood, J. G., Mirra, S. S., Pollock, N. J., and Binder, L. I. (1986). Neurofibrillary tangles of Alzheimer disease share antigenic determinants with the axonal microtubule-associated protein tau (tau). Proc. Natl. Acad. Sci. U.S.A. 83, 4040-4043. doi: 10.1073/pnas.83.11.4040

Wood-Kaczmar, A., Gandhi, S., and Wood, N. W. (2006). Understanding the molecular causes of Parkinson's disease. Trends Mol. Med. 12, 521-528. doi: 10.1016/j.molmed.2006.09.007

Zhang, C. (2012). Natural compounds that modulate BACE1-processing of amyloid-beta precursor protein in Alzheimer's disease. Discov. Med. 14, 189-197.

Zhang, Y. W., Thompson, R., Zhang, H., and Xu, H. (2011). APP processing in Alzheimer's disease. Mol. Brain 4, 3. doi: 10.1186/1756-6606-4-3

Zhao, J., Sun, B. K., Erwin, J. A., Song, J. J., and Lee, J. T. (2008). Polycomb proteins targeted by a short repeat RNA to the mouse X chromosome. Science 322, 750-756. doi: 10.1126/science.1163045

Zhu, H. C., Wang, L. M., Wang, M., Song, B., Tan, S., Teng, J. F., et al. (2012). MicroRNA-195 downregulates Alzheimer's disease amyloidbeta production by targeting BACE1. Brain Res. Bull. 88, 596-601. doi: 10.1016/j.brainresbull.2012.05.018

Zimprich, A., Biskup, S., Leitner, P., Lichtner, P., Farrer, M., Lincoln, S., et al. (2004). Mutations in LRRK2 cause autosomal-dominant parkinsonism with pleomorphic pathology. Neuron 44, 601-607. doi: 10.1016/j.neuron.2004.11.005

Zomer, A., Vendrig, T., Hopmans, E. S., Van Eijndhoven, M., Middeldorp, J. M., and Pegtel, D. M. (2010). Exosomes: fit to deliver small RNA. Commun. Integr. Biol. 3, 447-450. doi: 10.4161/cib.3.5.12339

Zong, Y., Wang, H., Dong, W., Quan, X., Zhu, H., Xu, Y., et al. (2011). miR-29c regulates BACE1 protein expression. Brain Res. 1395, 108-115. doi: 10.1016/j.brainres.2011.04.035

Zuccato, C., Tartari, M., Crotti, A., Goffredo, D., Valenza, M., Conti, L., et al. (2003). Huntingtin interacts with REST/NRSF to modulate the transcription of NRSE-controlled neuronal genes. Nat. Genet. 35, 76-83. doi: 10.1038/ ng1219

Zuccato, C., Valenza, M., and Cattaneo, E. (2010). Molecular mechanisms and potential therapeutical targets in Huntington's disease. Physiol. Rev. 90, 905-981. doi: 10.1152/physrev.00041.2009

Conflict of Interest Statement: The authors declare that the research was conducted in the absence of any commercial or financial relationships that could be construed as a potential conflict of interest.

Received: 27 June 2013; accepted: 03 December 2013; published online: 19 December 2013.

Citation: Maciotta S, Meregalli M and Torrente Y (2013) The involvement of microRNAs in neurodegenerative diseases. Front. Cell. Neurosci. 7:265. doi: 10.3389/fncel. 2013.00265

This article was submitted to the journal Frontiers in Cellular Neuroscience. Copyright (C) 2013 Maciotta, Meregalli and Torrente. This is an open-access article distributed under the terms of the Creative Commons Attribution License (CC BY). The use, distribution or reproduction in other forums is permitted, provided the original author(s) or licensor are credited and that the original publication in this journal is cited, in accordance with accepted academic practice. No use, distribution or reproduction is permitted which does not comply with these terms. 